\title{
Blue light phototoxicity toward human corneal and conjunctival epithelial cells in basal and hyperosmolar conditions
}

\author{
Veronika Marek ${ }^{\mathrm{a}, \mathrm{b}, *}$, Stéphane Mélik-Parsadaniantz ${ }^{\mathrm{b}}$, Thierry Villette ${ }^{\mathrm{a}}$, Fanny Montoya ${ }^{\mathrm{a}}$, \\ Christophe Baudouin ${ }^{\mathrm{b}, \mathrm{d}, \mathrm{d}}$, Françoise Brignole-Baudouin ${ }^{\mathrm{b}, \mathrm{c}, \mathrm{e}}$, Alexandre Denoyer ${ }^{\mathrm{b}, \mathrm{c}, \mathrm{f}}$

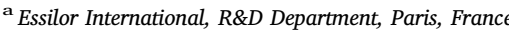 \\ b Sorbonne Université, INSERM, CNRS, Institut de la Vision, Paris, France \\ ' Centre Hospitalier National d'Ophtalmologie des Quinze-Vingts, Paris, France \\ ${ }^{\mathrm{d}}$ Versailles-Saint-Quentin-en-Yvelines Université, Versailles, France \\ e Sorbonne Paris Cité - Paris Descartes Université, Faculté de Pharmacie de Paris, Département de Toxicologie, Paris, France \\ ${ }^{\mathrm{f}} \mathrm{CHU}$ Robert Debré, Université Reims Champagne-Ardenne, Reims, France
}

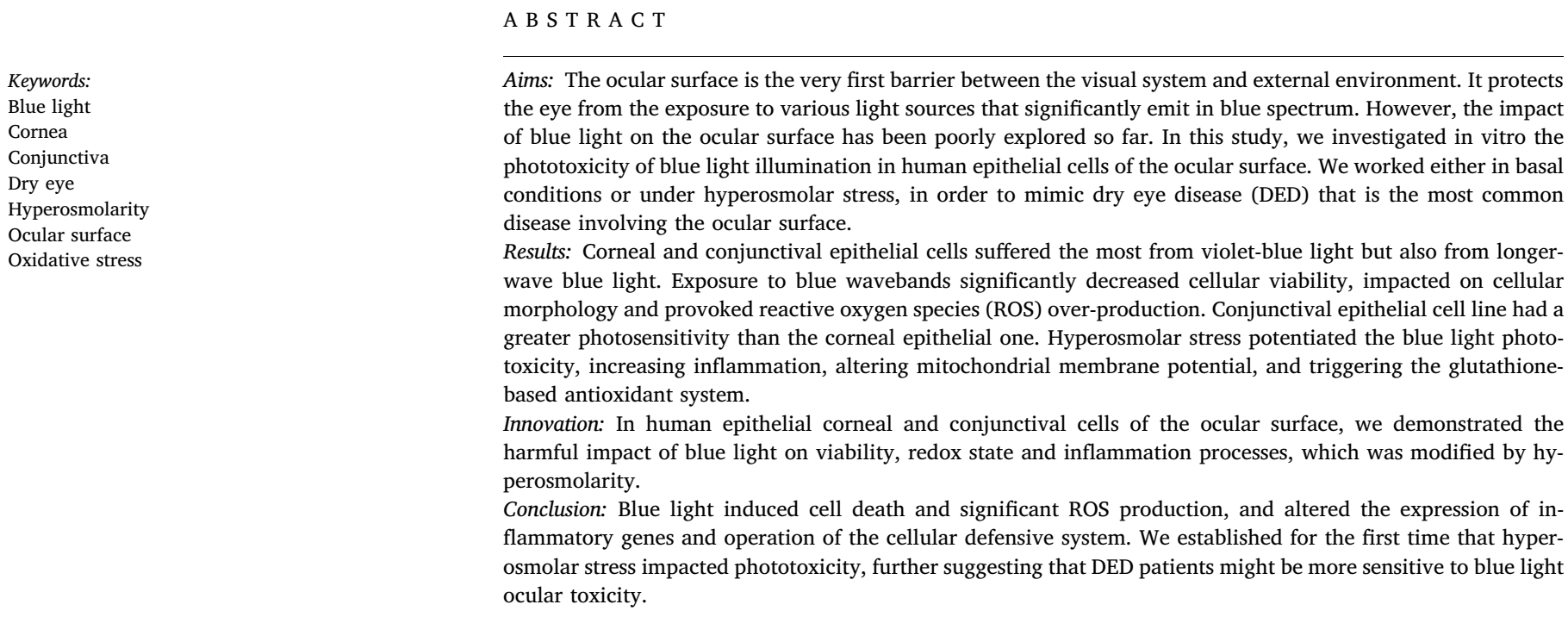

\section{Introduction}

Today it is widely discussed that blue light may provoke an important ocular phototoxicity [1]. Various blue and UV light-induced and/or -aggravated ocular pathologies have been recognized, including photokeratitis, pterygium, cataract, and corneal and retinal degeneration [2-6]. In particular, patients suffering from dry eye disease (DED) frequently complain about the exacerbated photosensitivity and increased symptoms of discomfort when exposed to various visible light sources [7,8]. According to the TFOS DEWS II report [9], dry eye is $a$ multifactorial disease of the ocular surface characterized by a loss of homeostasis of the tear film, and accompanied by ocular symptoms, in which tear film instability and hyperosmolarity, ocular surface inflammation and damage, and neurosensory abnormalities play etiological roles [10]. Today, DED is the current leading reason for ophthalmological consultations [11]; in dependence on the operational dry eye definition used and the

Abbreviations and sign: DED, Dry Eye Disease; HCE cell line, Human Corneal Epithelial cell line; HO, HyperOsmolar; HYP, Hoeschst/YO-PRO/PI; IOBA-NHC or IOBA cell line, cell line from Normal Human Conjunctiva; IR, InfraRed; MMP, Mitochondrial Membrane Potential; PI, Propidium Iodide; RT, Room Temperature; UVt, UltraViole; $\lambda \uparrow$, excitation wavelength (for fluorescence readings); $\lambda \downarrow$, emission wavelength (for fluorescence readings)

* Corresponding author at: Essilor International R\&D, F-75012 Paris, France.

E-mail address: marekv@essilor.fr (V. Marek). 
characteristics of the population studied, its prevalence varies from 5 up to $45 \%$ [7].. DED was initially recognized as a disease of aging people, however, the dry eye patients are currently getting younger [12]. Since younger generations spend a significant part of their day looking at various screens highly emitting in the blue spectrum $[13,14]$, this "rejuvenation" is not surprising. Indeed, there are numerous studies describing the appearance and/or worsening of DED signs and symptoms in visual display users [15-18].

The global pathogenesis of DED as well as the relationship between DED and exposure to visible light specifically are still not clear [19]. So far many works were dedicated to the dangerous role of light in retinal diseases; in particular, the detrimental effect of blue light on the retina has been extensively investigated [20-22]. However, little attention has been paid to the impact of blue light on the ocular surface, even though the cornea, the conjunctiva and the tear film represent the very first barrier between light and the entire visual system and are deeply involved in the pathophysiology of dry eye [19]. Among various tissues comprised in the ocular surface, cornea and conjunctiva are the structures the mostly exposed to the ambient environment and are probably the most susceptible to blue light [23]. In our daily life, our eyes are constantly illuminated by various types of artificial and natural sources, mainly ranging from UVA $(360 \mathrm{~nm})$ to IRA $(1400 \mathrm{~nm})$ and providing with an important blue irradiance. Several studies investigated the impact of near UV and IR light on the ocular surface [24-28] but only several ones analyzed the impact of blue light exposure [2,29-33]. Given our specialized practice in the clinical management of DED and previous basic studies on ocular surface inflammation and toxicity [34-37], we hypothesized about a potential harmful influence of blue light on the triggering and evolution of DED. Thus, the aim of this in vitro study was to investigate the impact of blue-light exposure on human epithelial cells of ocular surface, cultured either in basal conditions or additionally stressed by hyperosmolar conditions (HO) frequently used as an in vitro model of dry eye [38]. In particular, we studied the impact of various blue wavebands on cellular viability and health, oxidative stress, mitochondrial function and inflammatory cytokines expression.

\section{Results}

\subsection{Wide blue wavebands induced oxidative stress but did not affect the cellular viability}

First, we investigated the phototoxicity of wide spectral illumination directly after the end of light exposure. For both HCE and IOBA cell lines, neither blue $(380-525 \mathrm{~nm})$ nor yellow $(538-662 \mathrm{~nm})$ wavebands did not alter the cellular viability, either in basal or in HO conditions, as compared to the dark (Fig. 1). No morphological changes were observed either (Supplementary Fig. S1). Accordingly, we did not find any significant changes in fluorescent signals of markers of cellular proliferation (Hoechst), apoptosis (YO-PRO) and necrosis (Propidium Iodide [PI]) (Supplementary Fig. S2). However, the level of hydrogen peroxide $\left(\mathrm{H}_{2} \mathrm{O}_{2}\right)$ was significantly increased under blue light exposure while it was not observed under yellow light one (Fig. 1). Level of $\mathrm{H}_{2} \mathrm{O}_{2}$ in HCE was statistically higher than in IOBA. Moreover, HO pre-stimulation further enhanced the production of $\mathrm{H}_{2} \mathrm{O}_{2}$ in HCE cells compared to normal culture condition.

\subsection{Narrow wavebands of blue light provoked an important cellular death}

To determine which wavelengths are more phototoxic, we further exposed cells to specific narrow-waveband $(10 \mathrm{~nm})$ illuminations of the same irradiance as for the previously used wide spectra. HCE viability significantly decreased at $420 \mathrm{~nm}$ (Fig. 2A), to greater extent in $\mathrm{HO}$ than in basal conditions. The near-UV $390 \mathrm{~nm}$, used more like a positive control, drastically killed cells, as expected. Similarly, IOBA viability significantly decreased at 420 and $390 \mathrm{~nm}$, with a more important decrease in $\mathrm{HO}$ conditions at $390 \mathrm{~nm}$ (Fig. 2B). Interestingly, IOBA cells demonstrated two other significant changes: i) the viability modestly increased at $480 \mathrm{~nm}$ under $\mathrm{HO}$ stress, ii) at $630 \mathrm{~nm}$, viability in $\mathrm{HO}$ conditions was lower than in normal ones (while not significantly differing from the HO dark control). Additionally measured HYP (Hoechst, YO-PRO and PI) fluorescent signals were significantly increased at $390 \mathrm{~nm}$ but not at $420 \mathrm{~nm}$; HO conditions amplified this increase for HCE but inhibited it for IOBA (data not shown). Measured variations in viability were in accordance with the observed morphological changes appeared after exposure to various blue wavebands (Fig. S3).

\subsection{HCE succeeded to recover after the exposure to $420 \mathrm{~nm}$ illumination while IOBA did not}

To assess the ability of cells to recover, we monitored the cellular viability, cellular proliferation, and death rates 4 and $24 \mathrm{~h}$ in the dark after the end of exposure. In HCE, the deleterious impact of $420 \mathrm{~nm}$ exposure recovered with time after $4 \mathrm{~h}$ in the dark; however, it remained more severe under HO stress (Fig. 2A). IOBA cells retained the important impact of $420 \mathrm{~nm}$ illumination for both culturing conditions whatever the observation time (Fig. 2B). Interestingly, IOBA viability was significantly deteriorated by $\mathrm{HO}$ stress at $4 \mathrm{~h}$, but not after $24 \mathrm{~h}$ of recovery.

For both cell lines, the viability remained significantly decreased at $390 \mathrm{~nm}$ and demonstrated no difference between culturing conditions. Because the deleterious effect under $390 \mathrm{~nm}$ was too important, for both cell lines in a time-course analysis, it was not possible to restore viability with time (Fig. 2A, B). HCE recovered after the exposure to $420 \mathrm{~nm}$ in normal conditions but not in HO conditions (Fig. 2C). Surprisingly, HCE under HO stress demonstrated a small increase in viability in $24 \mathrm{~h}$ after the recovery from $430 \mathrm{~nm}$ illumination. On the contrary, in both conditions, IOBA viability significantly decreased in time after the $420 \mathrm{~nm}$ illumination (Fig. 2D). There were also small decreases for $430 \mathrm{~nm}$ in normal and for $480 \mathrm{~nm}$ in $\mathrm{HO}$ conditions.

Accordingly to viability rate, for both cell lines, rates of HYP fluorescent staining remained highly elevated after the $390 \mathrm{~nm}$ illumination (data not shown); the values significantly varied over time only for this wavelength (Fig. 3). During the recovery time, under normal conditions, HCE proliferation (Hoechst staining) monotonically increased in time while under $\mathrm{HO}$ conditions, the proliferation rate at $+24 \mathrm{~h}$ decreased as compared to $+4 \mathrm{~h}$ (Fig. 3A1, B1). Accordingly, their apoptosis level (YO-PRO) decreased over time in basal but not in HO conditions (Fig. 3A2, B2). On the contrary, apoptosis rate continued to increase in IOBA cells (Fig. 3C2, D2); cell proliferation dropped either in basal or in HO culturing (Fig. 3C1, D1). For both cell lines, the necrosis rate (PI) increased after $4 \mathrm{~h}$ of recovery then went down (Fig. 3A3, B3, C3, D3).

\subsection{Exposure to blue light induced oxidative stress and compromised the mitochondria}

Illuminations of $420 \mathrm{~nm}$ produced a significant increase in $\mathrm{H}_{2} \mathrm{O}_{2}$ level that was modulated by $\mathrm{HO}$ stress (Fig. $4 \mathrm{~A}, \mathrm{~B}$ ) $\mathrm{H}_{2} \mathrm{O}_{2}$ rate after exposure to $430 \mathrm{~nm}$ turned out to be mainly non-significant. In full compliance with the measured values of cellular viability and death, both cell lines displayed an important increase in the production of $\mathrm{H}_{2} \mathrm{O}_{2}$ under positive-control $390 \mathrm{~nm}$ illumination. HO stress weakened this production in HCE and strengthened it in IOBA. Follow-up of the hydrogen peroxide rate showed that for both cell lines in both conditions, $\mathrm{H}_{2} \mathrm{O}_{2}$ level significantly varied in time only after harmful 430, 420 and $390 \mathrm{~nm}$ illuminations (Fig. 4C, D; the values that did not vary in time are not shown). In HCE and in IOBA in normal conditions, ROS rate at $430 \mathrm{~nm}$ significantly decreased in time. Under $\mathrm{HO}$ stress, that was $420 \mathrm{~nm}$ exposure that provoked time alterations of $\mathrm{H}_{2} \mathrm{O}_{2}$. In HCE, recovery time allowed for its significant elimination while in IOBA, its rate only went up. After the exposure to $390 \mathrm{~nm}$, hydrogen peroxide 
HCE
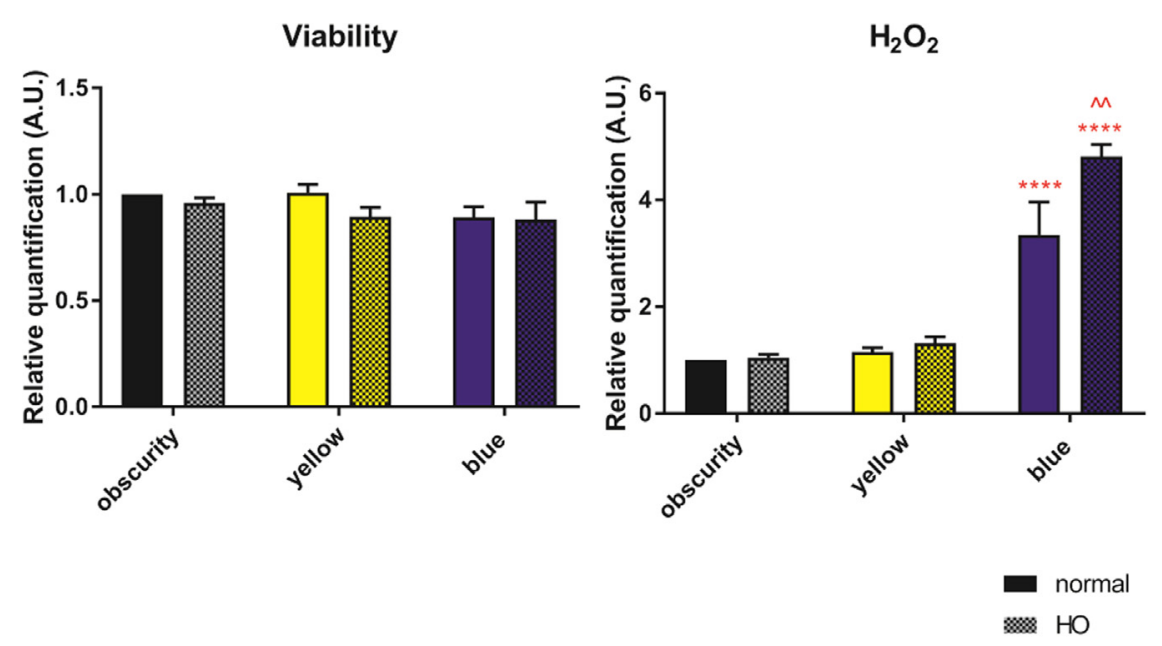

IOBA
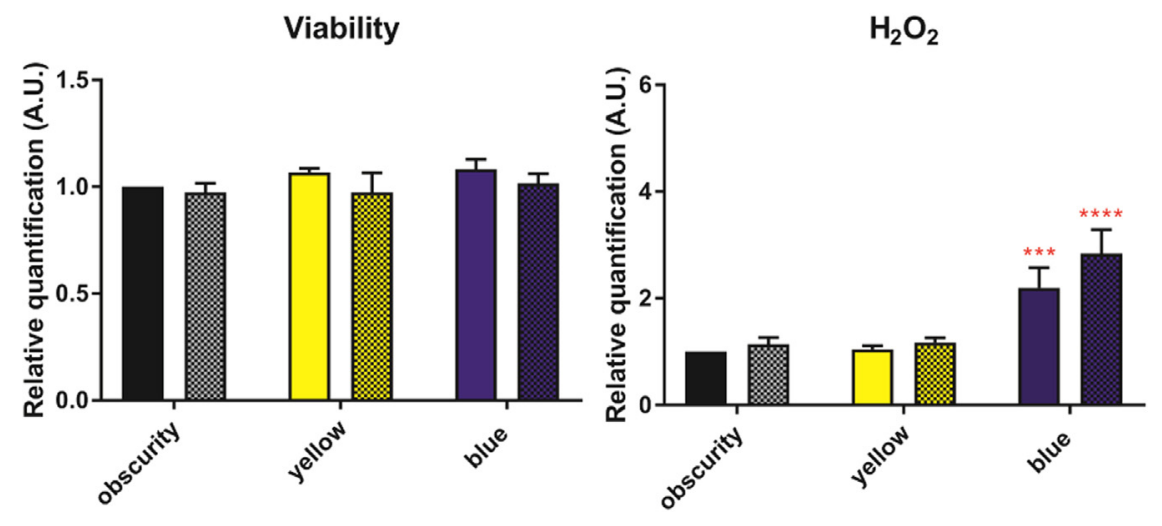

Fig. 1. Impact of wide-spectral illumination assessed directly after the end of exposure. Cellular viability and level of hydrogen peroxide generation $\left(\mathrm{H}_{2} \mathrm{O}_{2}\right)$ measured directly after $17 \mathrm{~h}$ of wide-spectral illumination. Control or illumination conditions are denoted by obscurity (cells kept in the dark), yellow (538-662 nm) and blue (380-525 nm). Clear bars correspond to normal and hatched bars to hyperosmolar $(\mathrm{HO})$ conditions of culturing. Results shown represent the mean \pm SEM. Stars $\left(^{*}\right)$ refer to differences with the correspondent dark control within the same culturing condition and carets $\left(^{\wedge}\right)$ refer to differences between culturing conditions (normal vs. HO) within the same light condition. Red signs correspond to an increase in values. Statistical significance: $\mathrm{p}<0.01\left(* * /{ }^{\wedge}\right), \quad \mathrm{p}<0.001$ $\left(* * * \mu^{\wedge n}\right), \mathrm{p}<0.0001\left(* * * * /^{\sim n n}\right)$. level remained highly elevated after either 4 or $24 \mathrm{~h}$ of recovery. For both cell lines, it increased in $4 \mathrm{~h}$ of recovery and then decreased again in $24 \mathrm{~h}$. These variations were more important in IOBA than in HCE.

Directly after the end of light exposure, we then explored the level of another important ROS, the mitochondrial superoxide anion $\left(\mathrm{O}_{2}{ }^{-}{ }^{-}\right)$. The $\mathrm{O}_{2}{ }^{\cdot}$ - rate was significantly increased after exposure to 430,420 and $390 \mathrm{~nm}$ (Fig. 5A, B). We observed an important fluorescent staining of oxidation products for the same wavelengths (Fig. 5C). For $390 \mathrm{~nm}$, under HO stress, the effect was weaker for HCE and stronger for IOBA.

Since we found a significant increase in mitochondrial oxidative stress level, we then studied another marker of cellular health that is the mitochondrial membrane potential (MMP). In IOBA in HO conditions, we observed a significant decrease in MMP under $420 \mathrm{~nm}$ illumination. Surprisingly, IOBA cell line demonstrated an unexpected increase of MMP after $430 \mathrm{~nm}$ exposure that was even more pronounced under $\mathrm{HO}$ stress. In basal conditions, IOBA also had a MMP increase at $480 \mathrm{~nm}$ (Fig. 6B). In HCE, MMP significantly decreased in cells illuminated by $390 \mathrm{~nm}$, with no difference between culturing conditions (Fig. 6A). The same decrease took place in IOBA cells. The measured values were in accordance with the observed fluorescent staining (Fig. 6C).

\subsection{Blue light phototoxicity impaired the antioxidant defensive system}

The highly important oxidative stress induced by light phototoxicity may trigger off the antioxidant system scavenging for ROS species. HCE demonstrated a modest significant increase in total glutathione (GSH) in $\mathrm{HO}$ conditions at $420 \mathrm{~nm}$. For both cell types at $390 \mathrm{~nm}$, we observed a significant increase in levels of both GSH and GSSG (oxidized glutathione). Under HO stress, this increase was less pronounced in HCE and more pronounced in IOBA cells (Fig. 5D1,2, E1,2). Interestingly, in HCE, further calculated GSH/GSSG ratio did not demonstrate any significant differences either between wavebands or between culturing conditions (Fig. 5A3), but one should notice important dispersion of the results for the $390 \mathrm{~nm}$. In IOBA, the ratio between total and oxidized glutathione was significantly increased at $390 \mathrm{~nm}$ with no difference between culturing conditions (Fig. 5B3).

\subsection{Blue light induced changes in mRNA expression of cytokines and antioxidants}

Because of the important cellular death, we were not able to process cells exposed to $390 \mathrm{~nm}$ light for the RT-qPCR (their number was not sufficient).

In HCE in basal conditions, mRNA expression of IL-6 was significantly up-regulated directly after exposure to 420 and $430 \mathrm{~nm}$. Under HO stress, the wavelength dependence of IL- 6 seemed to be qualitatively the same as in normal conditions. However, due to important fluctuations induced by HO medium, it appeared to be statistically non-significant (Fig. 7A1). In both culturing conditions, CXCL8 was up-regulated at $420 \mathrm{~nm}$ exposure, to a greater extent under $\mathrm{HO}$ stress (Fig. 7A2). Both TGF $\beta 2$ and CCL2 were down-regulated in normal conditions under 420, 430 and $480 \mathrm{~nm}$ illuminations. In HO conditions, the expression of both cytokines was significantly increased but with no spectral dependence (Fig. 7A3, A4). One should notice that the variations of TGF $\beta 2$ expression were quite low.

In IOBA cells, IL-6 expression did not vary, either in normal or in $\mathrm{HO}$ 
Oh

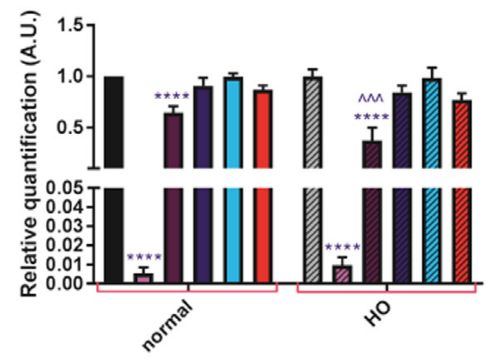

B

$\mathrm{Oh}$

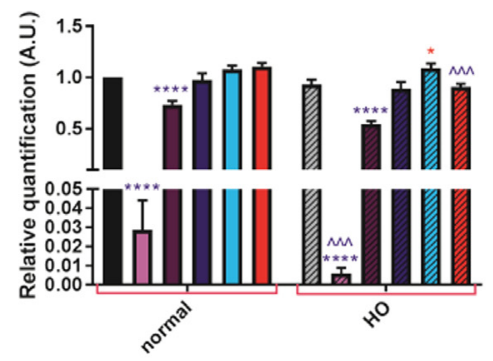

C

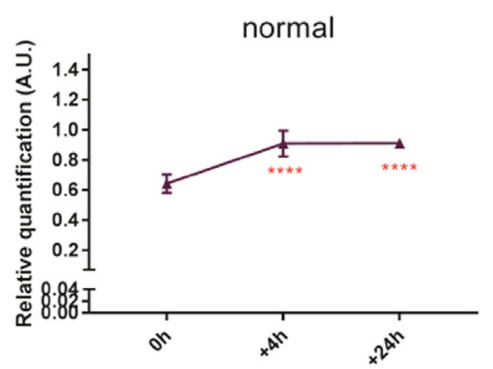

D

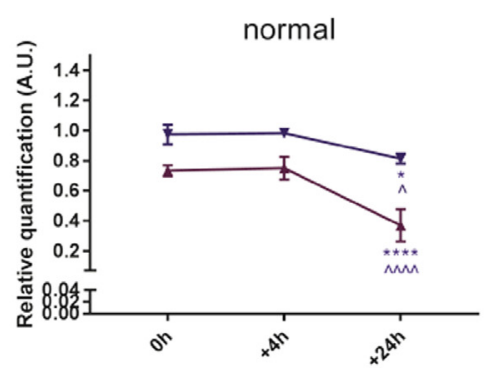

$+4 \mathrm{~h}$

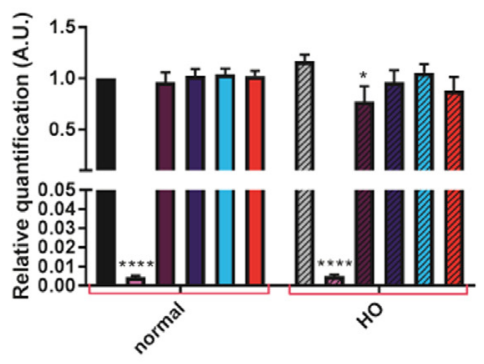

IOBA viability

$+4 \mathrm{~h}$

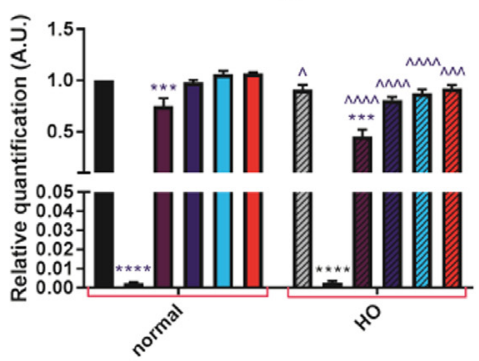

$+24 \mathrm{~h}$

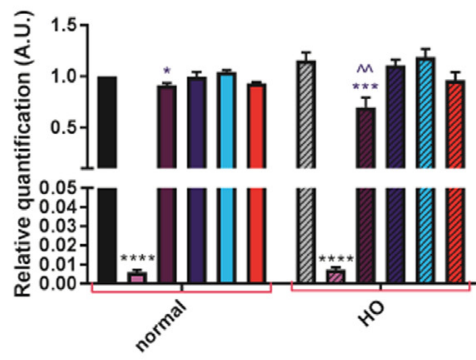

$+24 \mathrm{~h}$

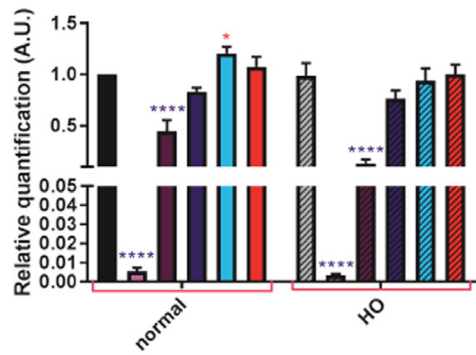

\section{HCE viability in time}

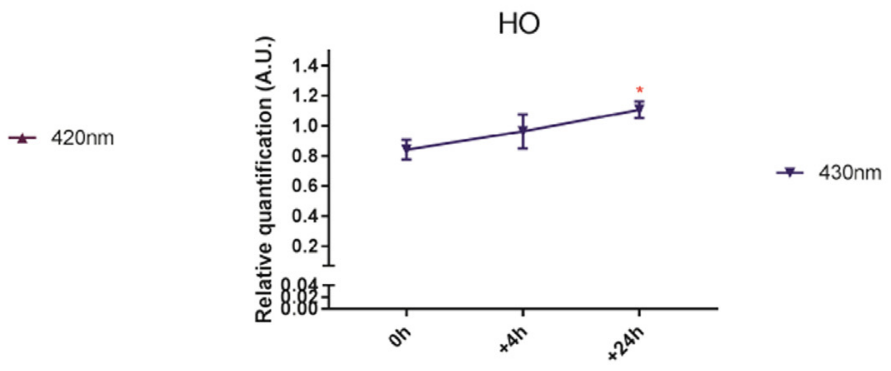

\section{IOBA viability in time}
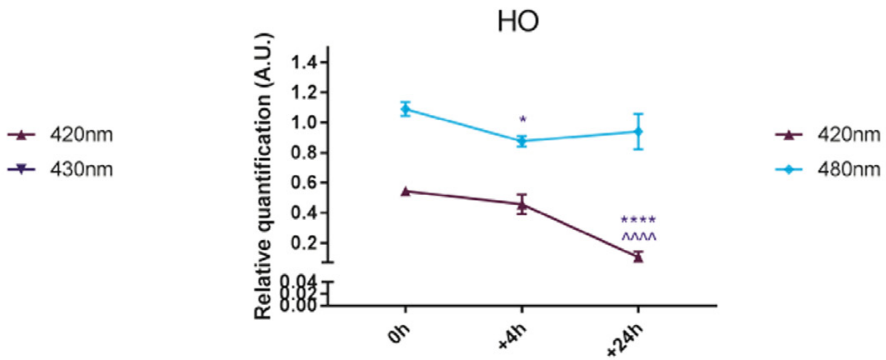

$\rightarrow 480 \mathrm{~nm}$

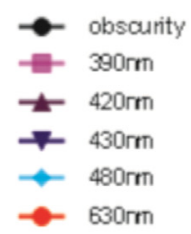

Fig. 2. Impact of narrow-spectral illumination on cellular viability and its further recovery. (A, B) Cellular viability measured directly after $17 \mathrm{~h}$ of narrowspectral illumination $(O h)$, then in $4(+4 h)$ or in $24(+24 h)$ hours of recovery in the dark. Clear bars correspond to normal and hatched bars to hyperosmolar $(H O)$ conditions of culturing. Wavebands are represented by the correspondent colors; they are denoted on the color code scheme where each $10 \mathrm{~nm}$ spectral band is designated by its central wavelength. Results shown represent the mean \pm SEM. Stars $(*)$ refer to differences with the correspondent dark control within the same culturing condition and carets $\left(^{\wedge}\right)$ refer to differences between culturing conditions (normal vs. HO) within the same light condition. Red signs correspond to an increase and blue signs to a decrease in values. Statistical significance: $\mathrm{p}<0.05(* \wedge), \mathrm{p}<0.01\left(* * /{ }^{\wedge}\right), \mathrm{p}<0.001\left(* * *{ }^{\wedge \wedge}\right), \mathrm{p}<0.0001\left(* * * * /{ }^{\wedge \wedge}\right) .(\mathrm{C}, \mathrm{D})$ Time course of viability recovery in normal or hyperosmolar conditions. Viability rates were measured directly after the end of exposure to light $(0 \mathrm{~h})$, then in $4(+4 \mathrm{~h})$ and in $24(+24 h)$ hours of recovery in the dark. Only the wavebands for which significant changes in time were observed are shown. Each $10 \mathrm{~nm}$ spectral band is designated by its central wavelength. Results shown represent the mean \pm SEM. For points for which the error bars are shorter than the height of the symbol, error bars are not drawn. Stars $\left(^{*}\right)$ refer to differences with values at $0 \mathrm{~h}$ time point and carets $\left.{ }^{\wedge}\right)$ refer to differences with values at $+4 \mathrm{~h}$ time point. Significances of change are denoted near the plot of the correspondent waveband at the correspondent time point. Red signs correspond to an increase and blue signs to a decrease in values. Statistical significance: $\mathrm{p}<0.05(* / \wedge), \mathrm{p}<0.0001(* * * * / \mu n)$. 


\section{HCE - HYP markers in time}

\section{normal}
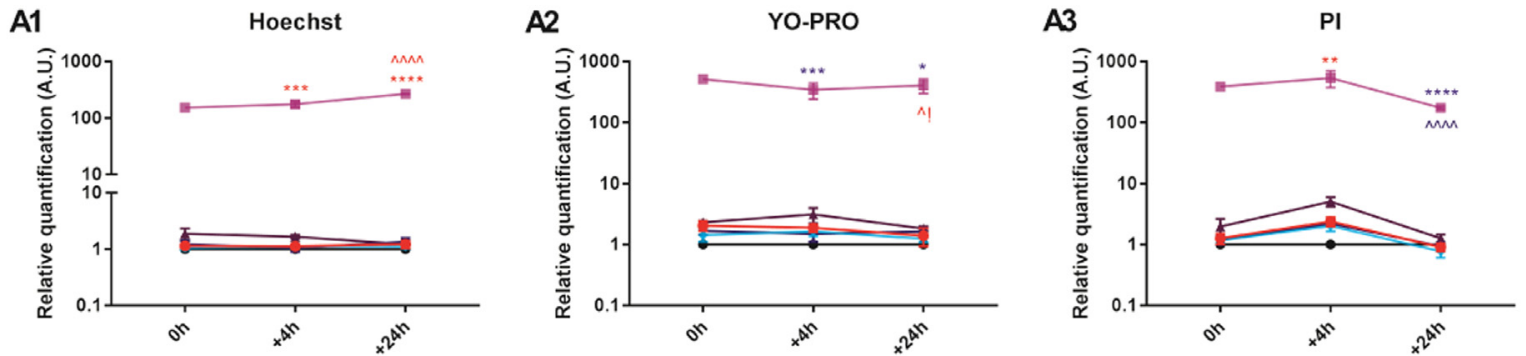

HO
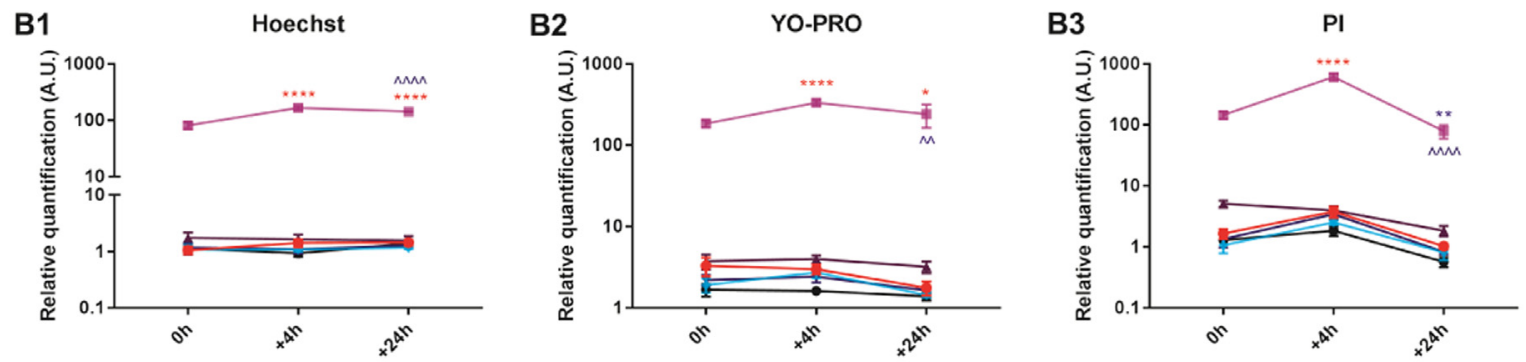

\section{IOBA - HYP markers in time}
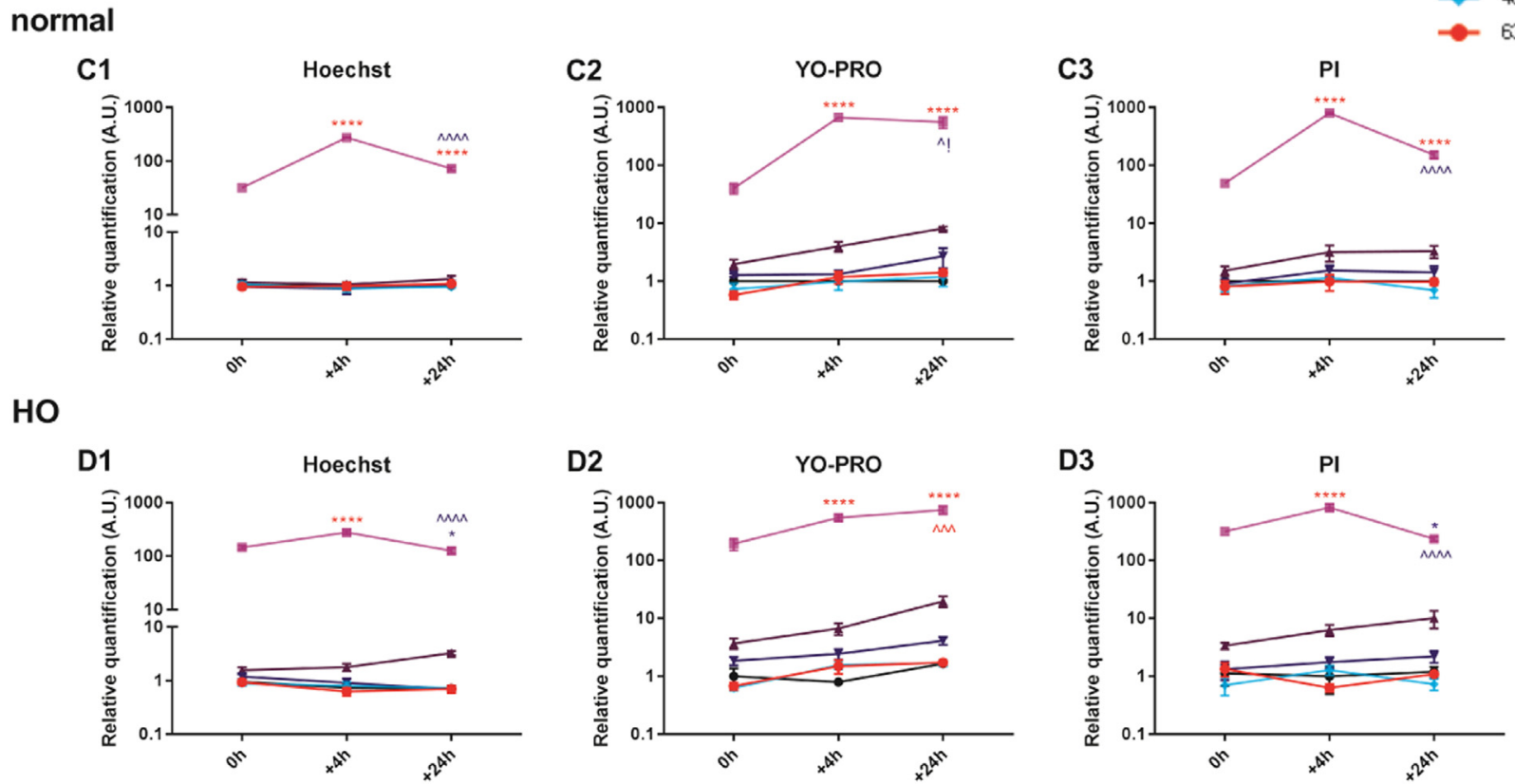

Fig. 3. Time changes in rates of cellular death after a narrow-spectral illumination. Time course of rates of cellular apoptosis (Hoechst - A1-D1, YO-PRO - A2D2) and necrosis (PI - A3-D3), in normal (A, C) and hyperosmolar (B, D) conditions. Measurements were done directly after the end of exposure to light $(0 \mathrm{~h})$, then in $4(+4 h)$ and in $24(+24 h)$ hours of recovery in the dark. Each $10 \mathrm{~nm}$ spectral band is designated by its central wavelength. Results shown represent the mean \pm SEM. For points for which the error bars are shorter than the height of the symbol, error bars are not drawn. Stars (*) refer to differences with values at $0 \mathrm{~h}$ time point and carets $\left({ }^{\wedge}\right)$ refer to differences with values at $+4 \mathrm{~h}$ time point. Significances of change are denoted near the plot of the correspondent waveband at the correspondent time point. Red signs correspond to an increase and blue signs to a decrease in values. Statistical significance: $\mathrm{p}<0.05(* \wedge)$, $\mathrm{p}<0.01\left(* *{ }^{\wedge}\right)$, $\mathrm{p}<0.001\left(* * *{ }^{\wedge \wedge}\right), \mathrm{p}<0.0001\left(* * *{ }^{\wedge \wedge \wedge}\right) . *$ ! or ^! mean that, according to the GraphPad notes, the individual p-value is greater than 0.05 in the third digit following the point, the observed difference remaining still statistically significant.

conditions (Fig. 7C1). CXCL8 was significantly down-regulated at 420 and $430 \mathrm{~nm}$, with no difference between culturing conditions (Fig. 7C2). TGF 32 expression decreased for 420 and $430 \mathrm{~nm}$ exposure in normal conditions. No statistically significant wavelength dependence was observed under HO stress; however, the value for $420 \mathrm{~nm}$ was greater than the one in the basal conditions (Fig. 7C3). The CCL2 values of cycle threshold $(\mathrm{Ct})$ being too high $(\sim 36-37)$, we did not consider them as reliable and therefore did not present. 
A

oh

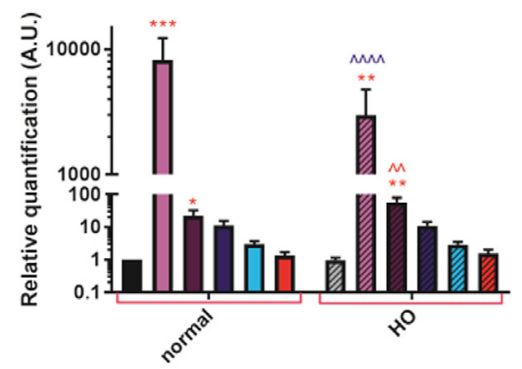

B

Oh

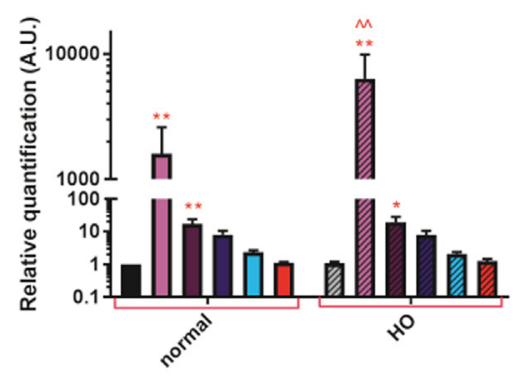

C

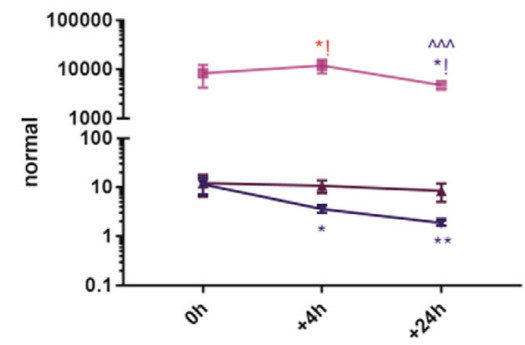

D

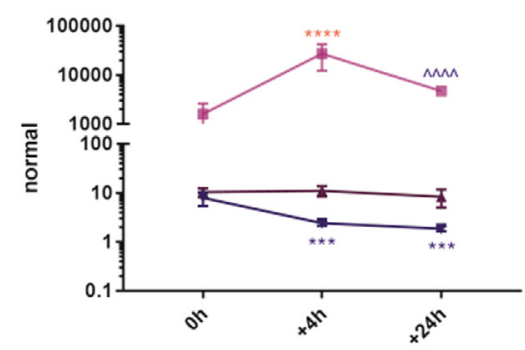

$\mathrm{H}_{2} \mathrm{O}_{2}$ in HCE

$+4 h$

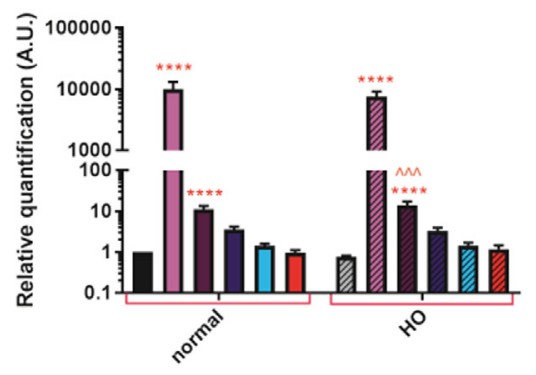

$\mathrm{H}_{2} \mathrm{O}_{2}$ in IOBA

$+4 \mathrm{~h}$
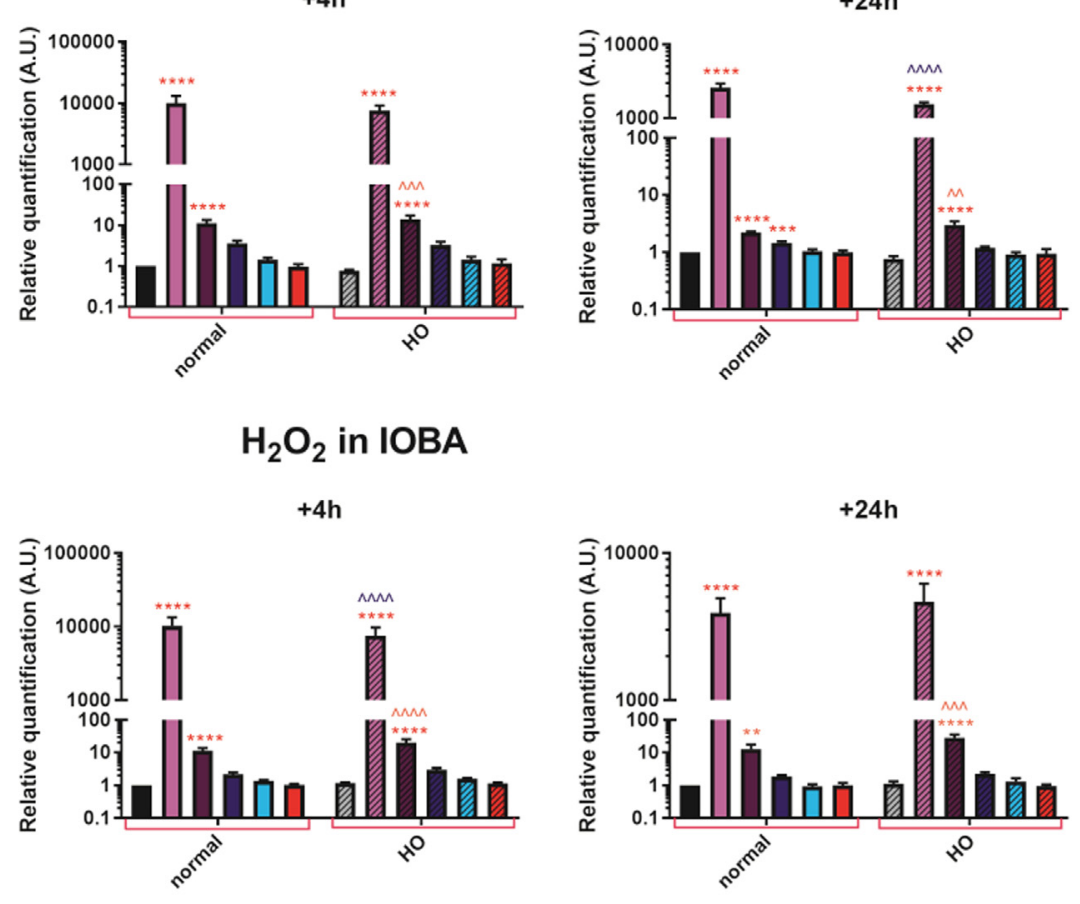

$\mathrm{H}_{2} \mathrm{O}_{2}$ in HCE in time

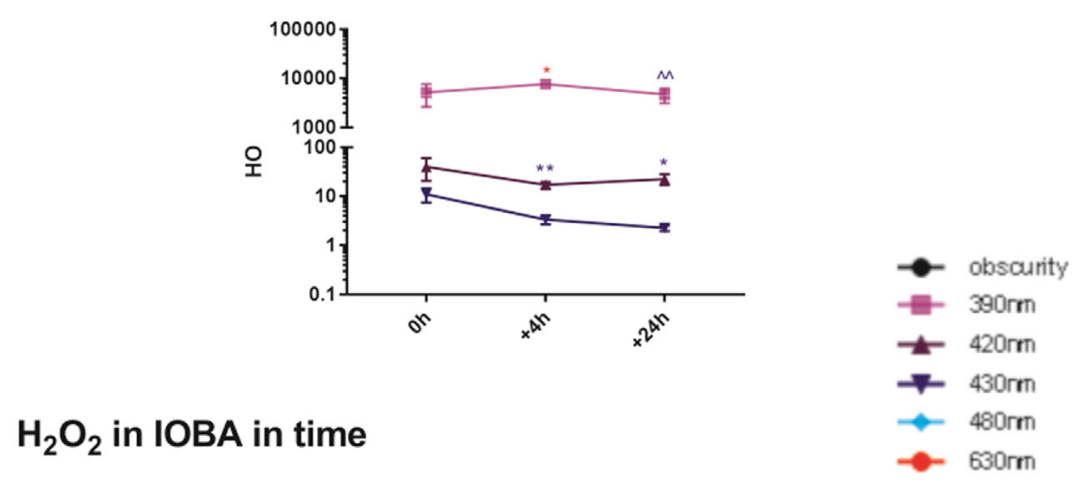

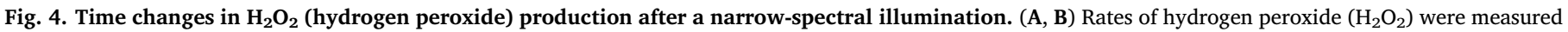

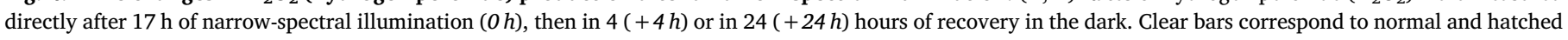

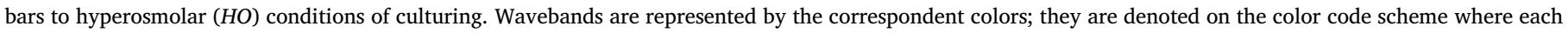

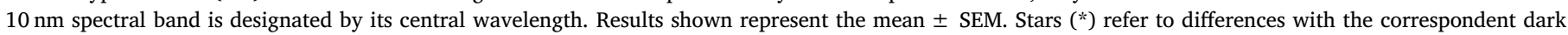

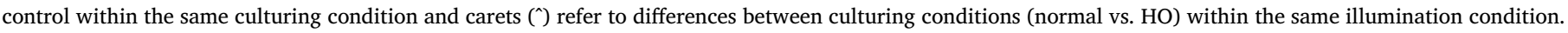

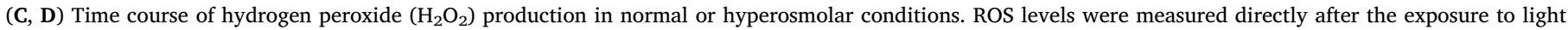

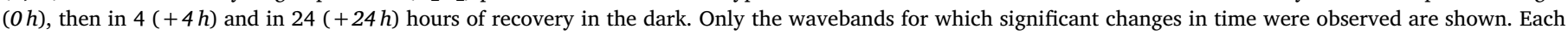

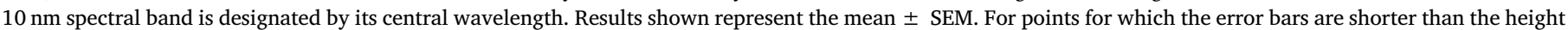

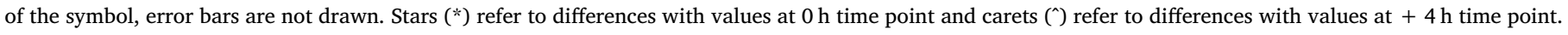

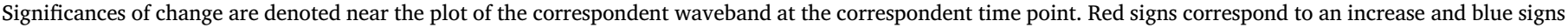

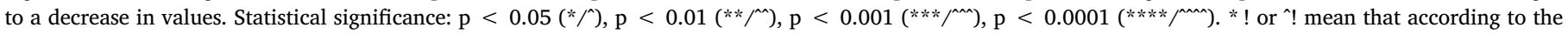
GraphPad calculations, the observed difference is still statistically significant, however, the correspondent $\mathrm{p}>0.05$. 


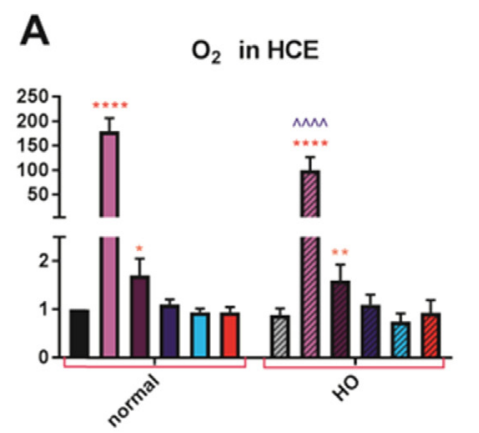

B
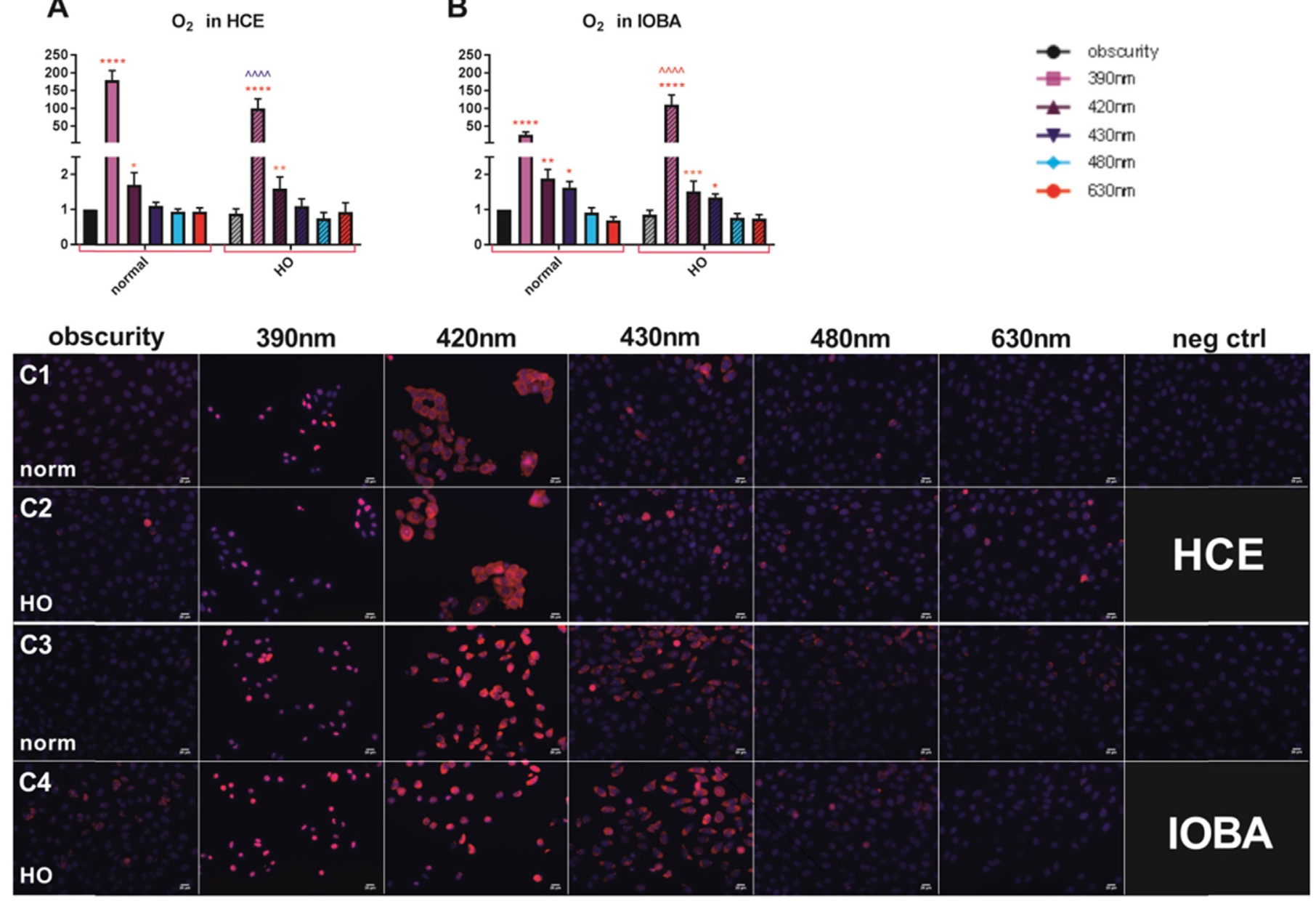

D1

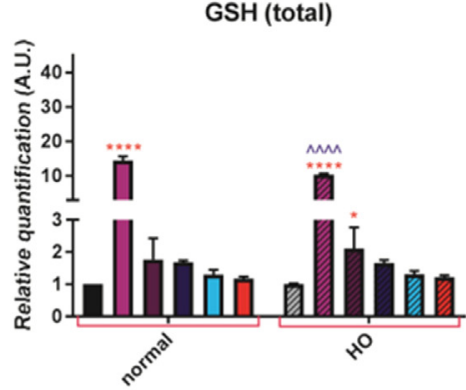

E1

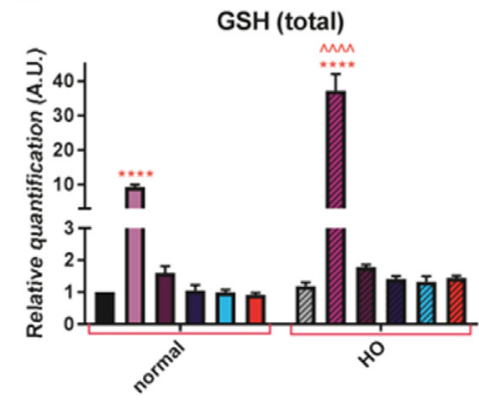

D2

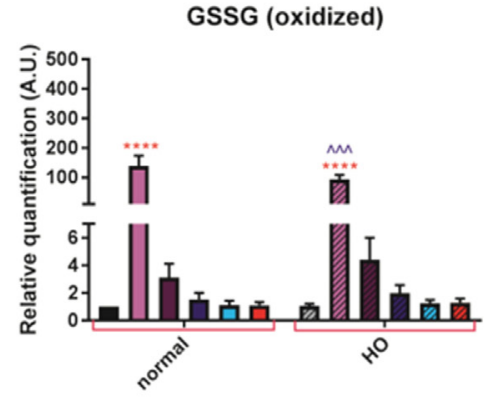

IOBA

E2

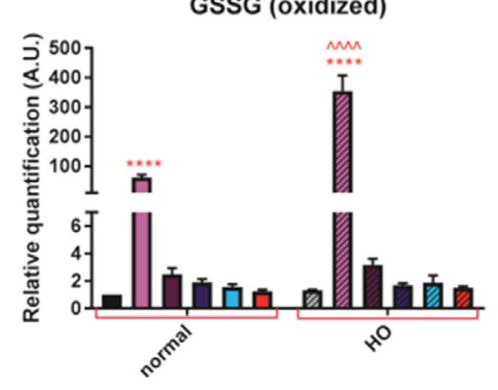

D3

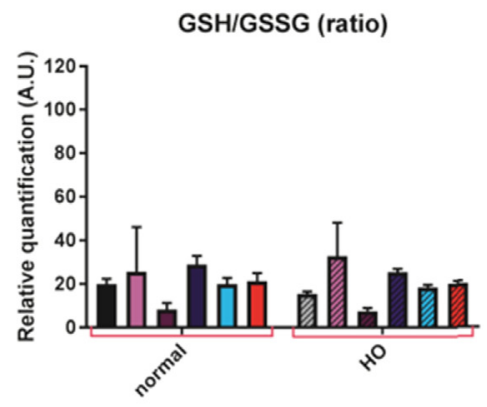

E3

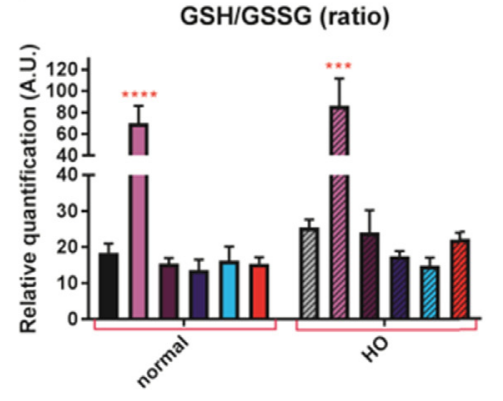




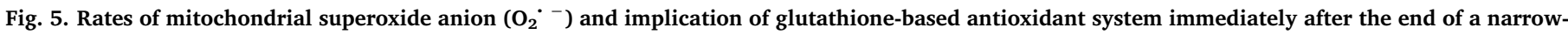

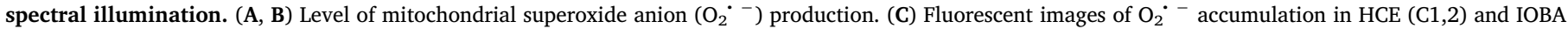

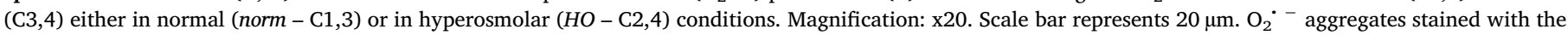

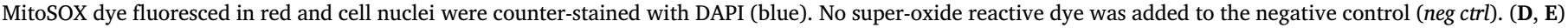

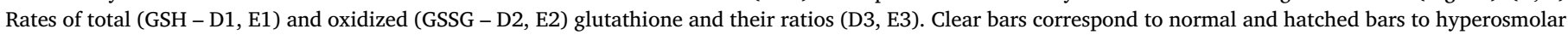

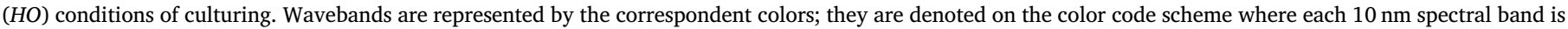

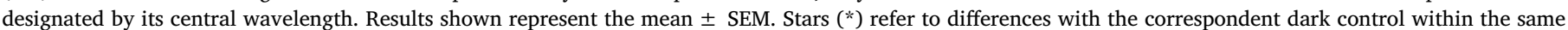

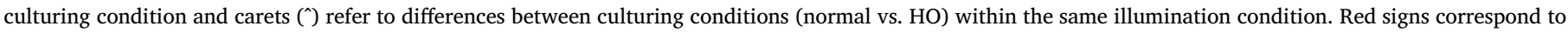

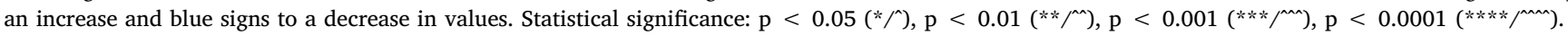

For both cell types, mRNA expression of NFkB did not demonstrate any spectral dependence. Nevertheless, under HO stress, it was significantly up-regulated at $420 \mathrm{~nm}$ for HCE and at $480 \mathrm{~nm}$ for IOBA as compared with basal conditions (Fig. 7B1, D1).

In HCE in normal conditions, GPx1 expression slightly decreased at $420 \mathrm{~nm}$. This value was significantly smaller than the one under HO stress (Fig. 7B2). In both culturing conditions, SOD1 was up-regulated at 420 and $430 \mathrm{~nm}$, to a more extent in $\mathrm{HO}$ conditions at $420 \mathrm{~nm}$ (Fig. 7B3). In IOBA, GPx1 was down-regulated at 420 and $430 \mathrm{~nm}$ in both culturing conditions with no difference between them; SOD1 did not vary (Fig. 7B2,D2).

\section{Discussion}

In clinical practice, environmental triggers such as light are known to potentially damage the ocular surface and aggravate dry eye signs, symptoms and the corresponding social impact [39]. This issue is even more important since today, in addition to sunlight, our life is highly illuminated by various light artificial sources. Here, we demonstrated in vitro the noxious and specific effects of visible violet-blue light on human epithelial cells of the ocular surface, and the influence of media osmolarity on this phototoxicity.

A

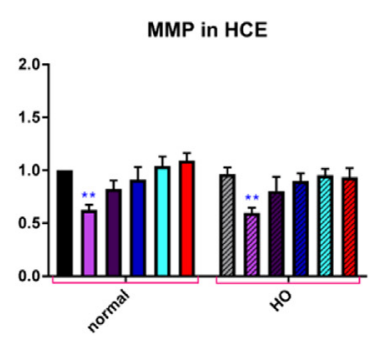

B

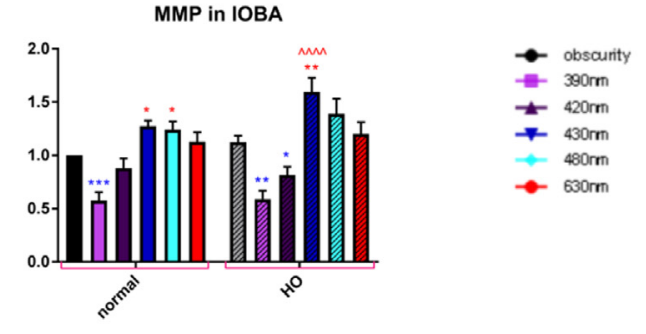

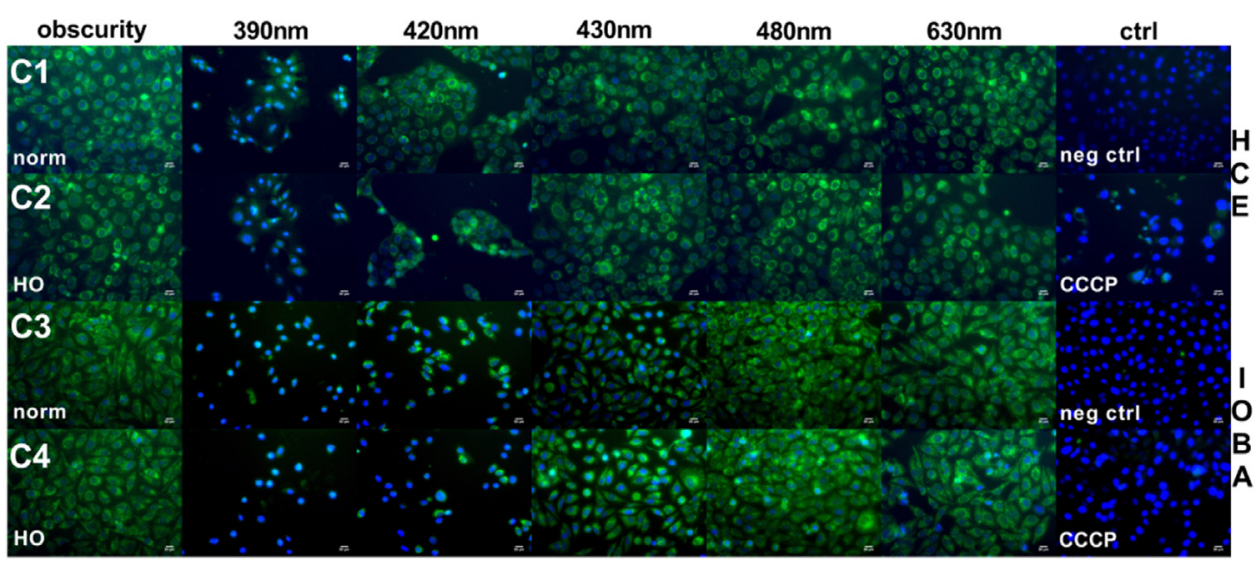

The originality of our work was to investigate and compare the phototoxicity on epithelial cells from the cornea and conjunctiva. These two main tissues of the ocular surface are the most exposed to the ambient environment and have fundamental roles in health and protection of the eye. In addition to the human corneal epithelial (HCE) cell line, the most widely used one for the in vitro studies of dry eye [40], we worked on a spontaneously immortalized epithelial cell line from normal human conjunctiva (IOBA-NHC) [41] which retains most of morphological and functional characteristics of human conjunctival epithelium [42,43]. Moreover, it was reported that IOBA line had a highly similar profile of biomarkers concerning cellular defense, communication and development when compared to primary culture of human conjunctival epithelial cells [42]. In order to mimic in vitro dry eye conditions, HO stress was applied to these cells [38]. To make HO media, we added $69 \mathrm{mM}$ of $\mathrm{NaCl}$ since greater values were reported to induce an important cell death $[38,44]$ and would probably bias the impact of light phototoxicity. The measured osmolarity values were within the range of the hyperosmolarity commonly used in experimental settings (e.g. $[38,45]$,). For both cell types, we decided to keep the same composition of culture media, in order not to induce an additional stress and to be able to assess the specific phototoxic effect. We used the irradiance range of wide-spectral illuminations that well 

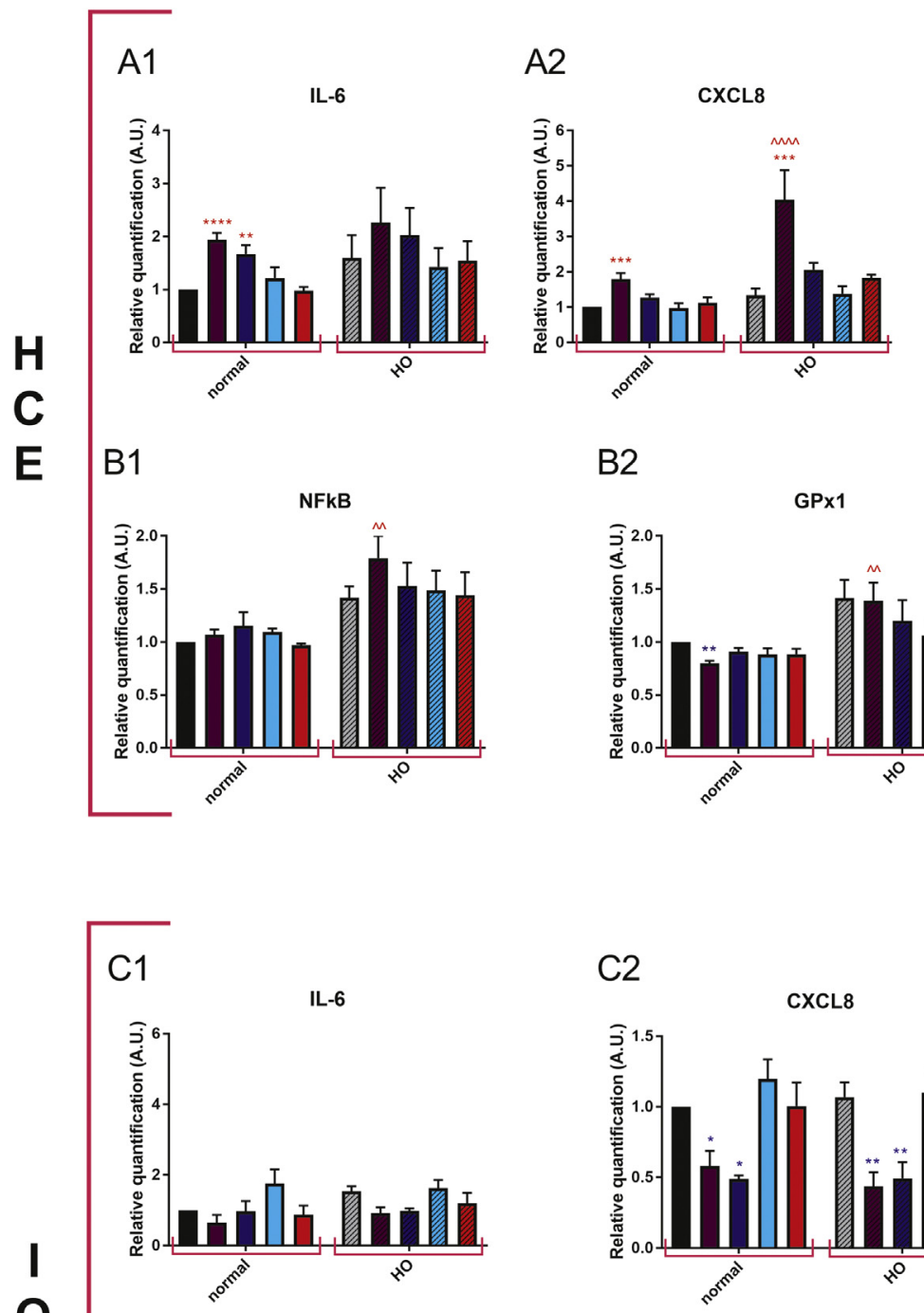

B

D1

A

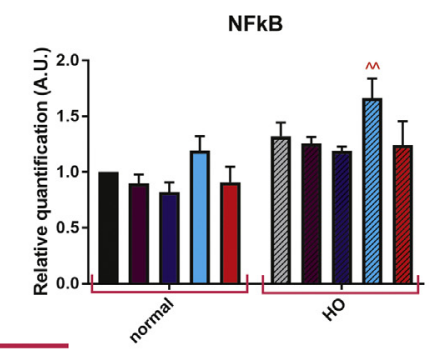

D2
A3

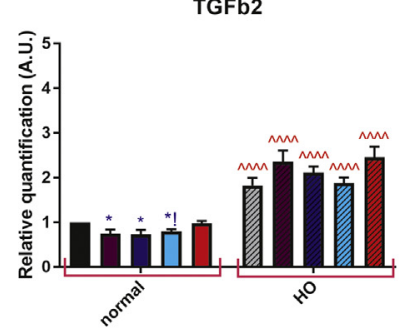

A4

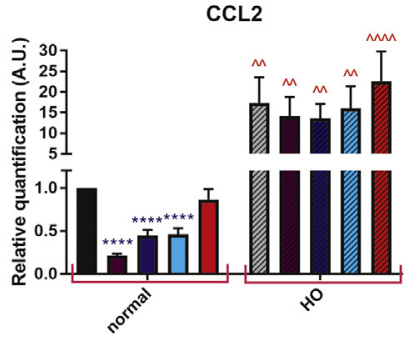

B3

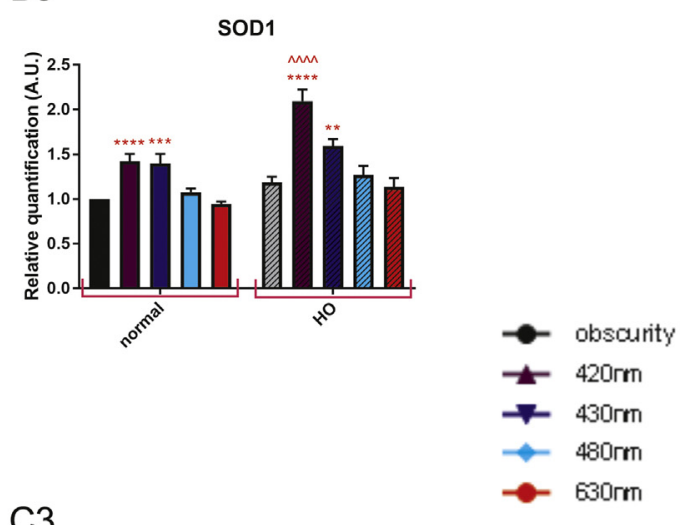

C3
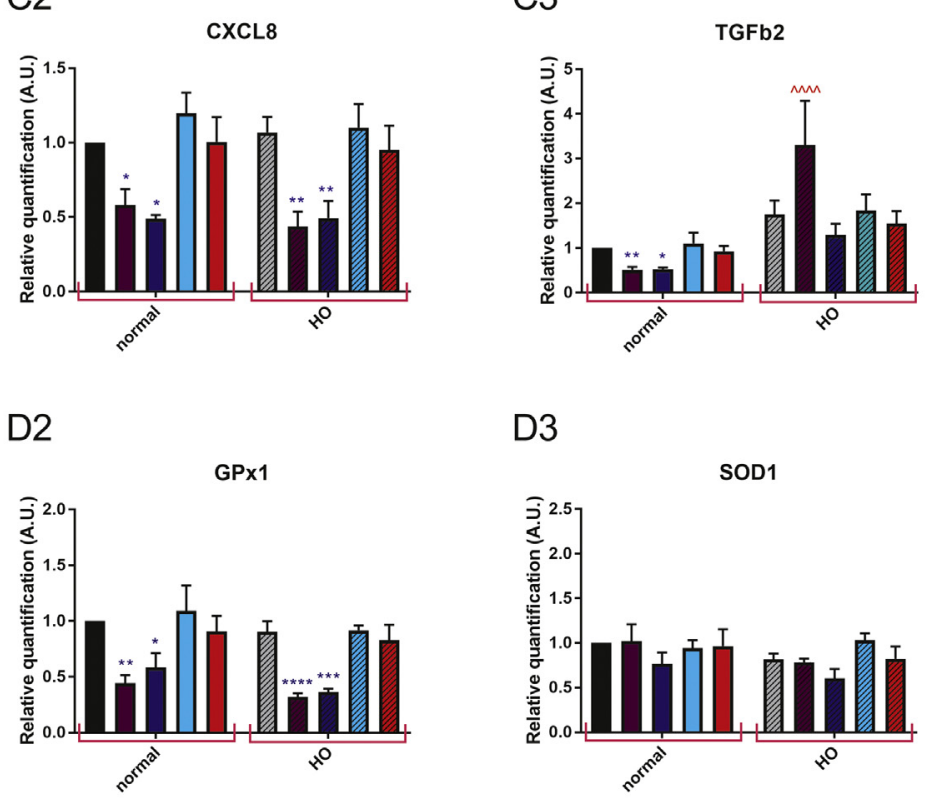

D3

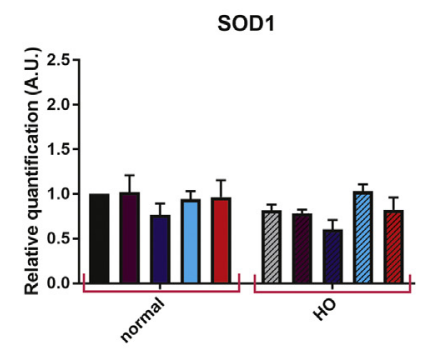

Fig. 7. Changes in mRNA expression levels measured immediately after the end of a narrow-spectral illumination. (A) IL-6, IL-8, TGF $\beta 2$, CCL2, (B) NFKB, GPx1, SOD1 in HCE; (C) IL-6, IL-8, TGFß2 (D) NFkB, GPx1, SOD1 in IOBA. Clear bars correspond to normal and hatched bars to hyperosmolar (HO) conditions of culturing. Wavebands are represented by the correspondent colors; they are denoted on the color code scheme where each $10 \mathrm{~nm}$ spectral band is designated by its central wavelength. Results shown represent the mean \pm SEM. Stars (*) refer to differences with the correspondent dark control within the same culturing condition and carets ( ${ }^{\wedge}$ ) refer to differences between culturing conditions (normal vs. HO) within the same illumination condition. Red signs correspond to an increase and blue

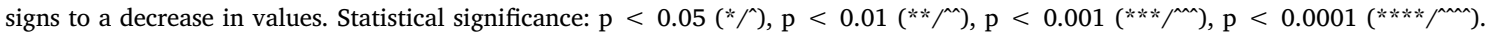

approximate the real-life conditions (Supplementary Fig. S4B1, B2). Indeed, according to recent measurements performed in the R\&D department of Essilor (publication currently in preparation), we can easily be exposed to $4.89 \mathrm{~mW} / \mathrm{cm}^{2}$ of a $380-780 \mathrm{~nm}$ ambient light when being outside on a sunny slightly cloudy day. This measurement corresponds to the entire visible solar spectrum $(380-780 \mathrm{~nm})$ while the irradiances 
of its blue (380-500 nm) and yellow (500-600 nm) spectral parts are $1.28 \mathrm{~mW} / \mathrm{cm}^{2}$ and $1.4 \mathrm{~mW} / \mathrm{cm}^{2}$ respectively. ${ }^{1}$ We set the time of illumination at $17 \mathrm{~h}$ since it is the average duration of wakefulness per day. This study demonstrated the phototoxicity of such wide-spectral blue illumination on the ocular surface in terms of increased ROS generation level.

Next, we explored the impact of narrow $10 \mathrm{~nm}$ wavebands situated within the large blue spectrum to better understand the specific wavelength dependency of phototoxicity. As we were limited to 5 various wavelengths that could be used simultaneously (illumination system constraint), we chose the most violet blue one that was also supposed to serve as a positive control $(390 \mathrm{~nm})$, the blue light whose toxicity is currently widely discussed ( 420 and $430 \mathrm{~nm}$ ), the turquoise blue implicated in circadian rhythms $(480 \mathrm{~nm})$, and also the red light $(630 \mathrm{~nm})$. The part of the plate was always kept in the dark for the control condition.

We demonstrated the significant decrease in viability for blue-illuminated cells. Morphologically, both cell lines noticeably collapsed at $390 \mathrm{~nm}$ and presented alterations at 420 and sometimes at $430 \mathrm{~nm}$, even if the viability rate for the latter did not show a significant quantitative decline. These results are in line with those of Niwano et al., Ayaki et al. and Lee et al. who found a significant decrease in the viability of rabbit corneal epithelial cell lines [31], primary cultures of human ocular cells [30] and HCE cell line [29] respectively illuminated by $410 \pm 10 \mathrm{~nm}$ waveband (in average). As opposed to HCE line, no recovery after exposure was observed in $420 \mathrm{~nm}$-illuminated IOBA cells; moreover, their morphological alterations appeared to be more important than in HCE. Together these results may suggest that conjunctival cells are more prone to blue light phototoxicity than the corneal ones. This higher photosensitivity of IOBA cell line would be logical taking into account the ocular immunology. Indeed, the conjunctival epithelium is very rich in highly interconnected immunocompetent cells, which makes the conjunctiva the first location of the ocular inflammatory response. One of the main roles of the conjunctiva is to protect the "noble" corneal structure and to preserve its integrity and transparency that are essential for the correct visual function. On the contrary, the cornea benefits from the immune privilege (few immune cells, no blood vessels) and from the inhibition of inflammatory reactions. Thus, the conjunctiva naturally participates in the inflammation process to a much greater extent than the cornea and is therefore more responsive to phototoxic stress [46-48]. To better understand the pathways of occurring cellular death, we calculated the ratios between YO-PRO (apoptosis) and PI (necrosis) signals at various times after the end of illumination (Supplementary Fig. S6). For both cell types at $390 \mathrm{~nm}$, this ratio significantly increased at least at the end of the $24 \mathrm{~h}$ recovery. Thus, we concluded about the prevailing role of apoptosis in the post-illumination phototoxic processes. Additional HO stress did not allow HCE line to restore viability as it was possible in normal conditions; it also impacted the proliferation and apoptosis rate. In IOBA after $4 \mathrm{~h}$ of recovery, we observed the amplification of phototoxicity by concomitant $\mathrm{HO}$ stress suggesting that light exposure could enhance ocular surface damage observed in DED, further emphasizing the commonly observed susceptibility of dry eye patients to blue light exposure.

Oxidative stress and excessive ROS generation are widely considered as key factors in the pathogenesis of ocular surface diseases, and notably in DED [39,49-52]. Indeed, in our model we observed an important increase in $\mathrm{O}_{2}{ }^{-}$rate in mitochondria, the main source of electrons for reduction of molecular oxygen to $\mathrm{O}_{2}{ }^{-}$[53]. We than

\footnotetext{
${ }^{1}$ Measurements were done at 10 a.m. in the center Paris at the end of May; the measurement setup was installed on the 5th floor, the detector orientation corresponded to the $-15^{\circ}$ of the head lowering; given values represent the average of irradiances measured in the four main directions (North, Est, South, West).
}

showed that $\mathrm{H}_{2} \mathrm{O}_{2}$, a specie that is poorly reactive but critical for signaling systems $[53,54]$, followed exactly the same trend but to a greater extent (the smaller rates of superoxide anion were probably due to the fact that $\mathrm{O}_{2}{ }^{--}$was transformed into other ROS species). Since $\mathrm{H}_{2} \mathrm{O}_{2}$ production demonstrated very important values, we than followed its rate in time. The peak observed for $390 \mathrm{~nm}$ in $4 \mathrm{~h}$ after exposure correlated with the previously detected peak of necrosis at that time point. At $420 \mathrm{~nm}, \mathrm{H}_{2} \mathrm{O}_{2}$ rate remained steady while it significantly decreased at $430 \mathrm{~nm}$, highlighting the greater toxicity of $420 \mathrm{~nm}$ illumination as compared to the $430 \mathrm{~nm}$ one. Our results concerning the ROS production are in agreement with those of Lee [29] and Ayaki [30]. Interestingly, in some experiments (cellular death rates and ROS production) in normal culturing conditions, the rates of immediate HCE cells' responses were stronger than IOBA cells' ones while there was no such a difference after recovery time. We therefore propose that in IOBA cells, the phototoxic process takes more time to activate the response of the same order than in HCE. Thus, the IOBA cell defense system cannot be switched on enough quickly making the conjunctival cells more sensitive to the impact of light. Indeed, the conjunctival tissues are more protected by eyelids than the corneal ones; that means that naturally the conjunctiva is supposed to be less illuminated by light than the cornea and may therefore posses a less adapted defense system.

Since oxidative stress is a result of an imbalance between free radical generation and scavenging, we further explored the functioning of ROS-eliminating system. In order to increase their antioxidant capacity [55], both cell lines triggered off their glutathione-based antioxidant system by increasing the levels of GSH and GSSG. As opposed to HCE, IOBA cells illuminated by blue-violet light demonstrated a significant increase in GSH/GSSG ratio, which is considered to determine the oxidant/anti-oxidant balance [56,57]. It suggests that in IOBA, the conjunctival anti-oxidant system was impaired, in agreement with already discussed greater photosensitivity of IOBA cells. Also, because ROS accumulation is known to be produced in mitochondria, we then checked the state of the mitochondrial membrane potential. In keeping with the previous results, for more violet exposures, we detected the loss of MMP that is considered to be a sensitive indicator of mitochondrial damage $[58,59]$. Surprisingly, IOBA cells demonstrated a significantly increased MMP after the $430 \mathrm{~nm}$ illumination. Even if the disruption of MMP is frequently considered as an important landmark in apoptotic signaling [60], numerous studies reported an increase in MMP as the very first response to stress. They suggest that mitochondrial hyperpolarization and ROS production precedes the decrease in MMP and represents an early event in apoptosis; the underlying cellular mechanism is though still incompletely understood (reviewed in $[61,62])$. Thus, the literature led us to suppose that $430 \mathrm{~nm}$ illumination may provoke early signs of cytotoxicity. MMP elevation was observed in various cell types (e.g., in T cells, HeLa cells, fibroblasts and astroglial cells, for more detail see [63-66]); however, no data are available concerning mitochondrial hyperpolarization in cells of the ocular surface. Together, our results suggest that $430 \mathrm{~nm}$ light, while being definitely less dangerous than its more short-wavelength visible counterparts, is still phototoxic to the ocular surface.

Combination of light exposure with HO stress is one of the main innovative points of our study. While being enough harmful for IOBA, in HCE, additional hyperosmolarity provides with a priming effect stimulating the HCE defense system and allowing cells for better struggle against phototoxicity. This effect may be explained by the hormesis theory [67] according to which, exposure to low continuous or higher intermittent doses of a stress agent, that would otherwise be harmful at larger or chronic doses, promotes favorable biological adaptations which protect against greater subsequent stress [68]. This concept is particularly extended to the mitochondria (mitohormesis) supposing that mild perturbations in mitochondrial homeostasis coordinate nuclear and cytosolic responses that make the whole cell less susceptible to future perturbations [68] (reviewed in $[69,70]$ ). Thus, we suggest that preexisting hyperosmolar stress provoked a mild oxidative stress 
which further played a role of perturbation necessary for mitohormesis. As a result, this process made HCE cells more adapted for struggling against phototoxicity. Nevertheless, this trigger factor turned out to be outside the hormetic zone for more sensitive conjunctival cells, thus providing IOBA with more important cytotoxicity.

Last, we investigated the mRNA expression for genes whose regulation is widely implicated in DED. Chemokine CXCL8, one of the major mediators of the inflammatory response, and proinflammatory cytokine IL-6 are important biomarkers of ocular surface inflammation and DED [71]. While being expectedly up-regulated in blue-illuminated HCE, in IOBA, CXCL8 expression went down. We ascribed this fact to a possible negative loop regulation that turned on when highly stressed IOBA cells produced CXCL8 in excess amount. Two other cytokines implicated in the ocular surface homeostasis and inflammation are CCL2 and TGF $\beta 2$. The former is produced by a variety of cell types, either constitutively or after induction by oxidative stress [72,73]. Our team has previously studied the induced expression of chemokines in the inflamed ocular surface; more particularly, in case of ocular surface toxicity induced by benzalkonium chloride, the deregulation of CX3CL1 and CCL2 in the conjunctival epithelium was demonstrated [37]. Together with TGF $\beta 2$, one of the most important ligands involved in modulation of cell behavior in ocular tissues [74], these markers were down-regulated in normal conditions. However, additional HO stress probably broke down the negative loop regulation leading to a significant increase in their expression. HO also slightly increased the expression NFkB, a protein complex that controls transcription of DNA, cytokine production, and cell survival, in accordance with previous studies where $\mathrm{NF \kappa B}$ was reported to have a role in HO-induced cellular signaling $[38,75]$. In HCE, the observed mRNA up-regulation of SOD1, one of the main antioxidant enzymes [57,76], meaning a setting-up of cellular defense system, even better adjusted under HO hormetic effect. On the opposite, in IOBA, no changes for SOD1 together with downregulation of GPx1 led again to a greater phototoxicity in this cell line. Together, these experiments allowed to observe the blue-light-induced alterations in mRNA expression of biomarkers implicated in the inflammatory response and antioxidant defense of ocular surface cells.

To sum up, we hypothesize that when blue light reaches the cell, it primarily impacts the mitochondria, increasing the rate of superoxide anion and changing its membrane potential. $\mathrm{O}_{2} \cdot{ }^{-}$is then transformed into hydrogen peroxide by means of superoxide dismutase $\cdot \mathrm{H}_{2} \mathrm{O}_{2}$ is further partially expulsed from the cell thus increasing the level of extracellular ROS. In cytosol, hydrogen peroxide is eliminated by means of glutathione-based defensive system. In addition, induced oxidative stress affects the regulation of inflammatory cytokines and of genes responsible for the functioning of the antioxidant system. One should note that the majority of harmful effects observed in this work were not detected after exposure to the control red light, thus confirming the blue wavelength specificity of the presented phototoxic effects. Moreover, it is worth to note that our findings are in line with recent in vivo results of Lee et al. who reported that overexposure to blue light induced oxidative damage and apoptosis to the cornea, probably resulting in increased ocular surface inflammation and dry eye [2].

Our work demonstrates the deleterious effects of blue light on the eye, not only on the retina but on the ocular surface. In vivo studies may confirm the present in vitro results including the role of various cell types such as goblet cells $[77,78]$ or potentially beneficial treatments like contrived tear products currently available on the market. Our findings corroborate the daily photosensitivity observed in DED patients in clinical practice, and show that they might be more prone to blue light phototoxicity. Wearing glasses that would filter out the blue wavebands the most toxic for the ocular surface and highly present in the given illumination conditions (like sunlight, office illumination, light from screens etc.) might provide DED patients with an important relief. In parallel, precisely adjusting the color spectrum in computer/ smartphone displays could also improve the symptoms and quality of life in patients with dry eye. Thus, a clinical study that would investigate such benefits is worth to be done.

\section{Materials \& methods}

\subsection{Cell lines}

The human corneal epithelial cell line (HCE, RCB-1384; Riken Cell Bank, Tsukuba, Japan) was cultured in DMEM/F12 no phenol red buffer (i.e., without photosensitizer), supplemented with $10 \%$ fetal bovine serum (FBS), 1\% penicillin (10,000 units/mL) and streptomycin $(10,000 \mu \mathrm{g} / \mathrm{mL})$ as described previously [40]. The IOBA-NHC cell line derived from normal human conjunctival epithelium [41] was cultured in DMEM/F12 no phenol red buffer supplemented with $1 \mathrm{~g} / \mathrm{mL}$ bovine pancreas insulin, $2 \mathrm{ng} / \mathrm{mL}$ mouse epidermal growth factor (EGF), $0.1 \mathrm{~g}$ / $\mathrm{mL}$ cholera toxin from vibrio cholerae, $5 \mathrm{~g} / \mathrm{mL}$ hydrocortisone suitable for cell culture, $10 \%$ fetal bovine serum (FBS), $1 \%$ penicillin $(10,000$ units $/ \mathrm{mL})$ and streptomycin $(10,000 \mu \mathrm{g} / \mathrm{mL})$ as described previously [37]. DMEM/F12 no phenol red (i.e., without photosensitizer), FBS, penicillin and streptomycin were purchased from Gibco (Life technologies, Carlsbad, CA, USA); insulin, EGF, cholera toxin and hydrocortisone were purchased form Sigma Aldrich (St. Louis, MO, USA). Both cell lines were cultured under classic conditions (moist atmosphere, $5 \% \mathrm{CO}_{2}, 37^{\circ} \mathrm{C}$ ); cells from passages $2-15$ were used. Cells were seeded in black 96-well plates (Greiner Bio-One GmbH, Kremsmünster, Austria) $24 \mathrm{~h}$ before the beginning of light exposure, to achieve $60-70 \%$ confluence. We choose this confluence since it was reported that confluent cells (90-100\%) may demonstrate no reduction in viability after the light exposure [31]. Moreover, if the cells have already reached the full confluence by the beginning of illuminatoin, they would undergo certain cell death independently on light impact, thus making it complicated to discern the purely phototoxic effect.

\subsection{Hyperosmolar conditions}

Hyperosmolar media were prepared by adding $69 \mathrm{mM}$ of sodium chloride (Sigma-Aldrich, St. Louis, MO, USA) to supplemented media. Osmolarity values of normal (basal) and hyperosmolar (HO) media were measured with an osmometer (Roebling 13DR, Berlin, Germany):

$\mathrm{HCE}($ basal $)=315 \mathrm{mOsm}, \quad \mathrm{HCE}(\mathrm{HO})=442 \mathrm{mOsm} \Rightarrow \triangle\left(\mathrm{HCE}_{\mathrm{HO} \text { stress }}\right)=127 \mathrm{mOsm}$ $\operatorname{IOBA}($ basal $)=324 \mathrm{mOsm}, \quad \operatorname{IOBA}(\mathrm{HO})=455 \mathrm{mOsm} \Rightarrow \triangle\left(\right.$ IOBA $\left._{\text {HOstress }}\right)=131 \mathrm{mOsm}$

\subsection{Light emitting devices and protocol}

\subsubsection{Wide-spectral illuminations - WL-Box device}

Cells were exposed to either blue $(380-525 \mathrm{~nm})$ or yellow (538-662 nm) light provided by a custom-made xenon-based device; the average irradiance was $1.15 \mathrm{~mW} / \mathrm{cm}^{2}$ (Supplementary Fig. S3A1,2, $\mathrm{B} 1,2)$.

\subsubsection{Narrow-spectral illuminations - BL-Box device}

Cells were exposed to 5 various $10 \mathrm{~nm}$-wide light wavebands provided by a custom-made LED-based fibered device as described previously [20]. The central wavelengths of these wavebands were 390, 420, 430, 480 and $630 \mathrm{~nm}$; their irradiances were 1.05, 1.13, 1.16, 1.11 and $1.53 \mathrm{~mW} / \mathrm{cm}^{2}$ respectively (Supplementary Fig. S3A3, B3).

Cells in black 96 well-plate were exposed to either wide (WL-Box) or narrow (BL-Box) wavebands of light for $17 \mathrm{~h}$; for each experiment, one subdivision of a well plate was maintained in darkness. Seven hours before the exposure beginning, cell basal media were either changed to the hyperosmolar ones, or just renewed (Fig. S3C). Except for the follow-up time experiments, all the assessments of light phototoxicity were performed immediately after the end of illumination. When time 
changes were monitored (for cell viability, proliferation and death rates and for hydrogen peroxide production), after the end of light exposure, cells were kept in dark under standard conditions (moist atmosphere, $5 \% \mathrm{CO}_{2}, 37^{\circ} \mathrm{C}$ ) for either 4 or $24 \mathrm{~h}$.

\subsection{Quantification of cell viability and $\mathrm{H}_{2} \mathrm{O}_{2}$ generation}

The CellTiter-Glo ${ }^{\circledR}$ Assay and the ROS-Glo ${ }^{\mathrm{TM}} \mathrm{H}_{2} \mathrm{O}_{2}$ Assay (Promega, Madison, WI, USA) were multiplexed according to the manufacturer's protocol. Briefly, cells were incubated with $\mathrm{H}_{2} \mathrm{O}_{2}$ Substrate Solution for $3 \mathrm{~h}$ before the end of exposure. Then, half of the supernatant of the illuminated well plate (plate N1) was carefully transferred to another well plate (plate N2), without touching the adherent cells. Then, the CellTiterGlo Detection Solution was added to the plate N1 and the ROSGlo Detection Solution was added to the plate N2. Both plates were incubated at room temperature (RT) in the dark for $20 \mathrm{~min}$ before luminescence reading on an Infinite M1000 microplate reader (Tecan, Männedorf, Switzerland). Luminiscence values were normalized with respect to control cells considered as $100 \%$ viable. For ROS quantification, the values were also normalized with respect to viability.

\subsection{Cell death assays - HYP (Hoechst/YO-PRO/PI) test}

The apoptotic cells are permeable for YO-PRO ${ }^{\circledR}-1$ (Invitrogen, Eugene, Oregon, USA) while remaining non-permeable to Propidium Iodide (Interchim, Montluçon, France) which only stains necrotic cells $[79,80]$. Hoechst 33342 (Invitrogen, Eugene, Oregon, USA) is a DNAintercalating agent that may therefore represent the cellular proliferation. Unlike propidium iodide, it is not excluded by live or apoptotic cells. It has been observed that short exposure of cells to low concentrations of Hoechst leads to strong rapid labeling of apoptotic cells while live cells require much longer incubation time to obtain comparable fluorescence intensity. Thus, Hoechst labeling has been also proposed as an assay of apoptosis [81]. The reagents were mixed together in the PBS (Gibco, Life technologies, Carlsbad, CA, USA) at the following concentrations: Hoechst $-1 / 1000$, YO-PRO $-1 / 150$, PI - 1 / 15000. Such a mixing was possible since the tree dyes have different excitation/emission spectra (Fig. S5). At the end of light exposure, the well plate was centrifuged at $1500 \mathrm{rpm}$ during $5 \mathrm{~min}$. Media were carefully replaced with $100 \mu \mathrm{l}$ of prepared solution; the well plate was then incubated for $30 \mathrm{~min}$ at RT in the dark. Further, $100 \mu \mathrm{l}$ of PBS were added to wells; the well plate was centrifuged again (1500 rpm, $5 \mathrm{~min}$ ) and supernatants were replaced with $100 \mu \mathrm{l}$ of fresh PBS. Finally, the fluorescent signals were read on an Infinite M1000 microplate reader (Tecan, Männedorf, Switzerland) in the following order, to avoid crossexcitations if there were any (hardly probable): Hoechst $-\lambda \uparrow=350 \mathrm{~nm}$, $\lambda \downarrow=461 \mathrm{~nm}$; YO-PRO $-\lambda \uparrow=491 \mathrm{~nm}, \lambda \downarrow=509 \mathrm{~nm}$; PI $-\lambda \uparrow=535 \mathrm{~nm}$, $\lambda \downarrow=617 \mathrm{~nm}$. Measured values were normalized with respect to control cells considered as 1 and also to viability.

\subsection{Quantification of $\mathrm{O}_{2}{ }^{-}$generation}

Superoxide anion levels were quantified using the MitoSOX ${ }^{\mathrm{TM}}$ Red Mitochondrial Superoxide Indicator kit (Life Technologies, Carlsbad, CA, USA). MitoSOX reagent working solution $(5 \mu \mathrm{M})$ was prepared by diluting MitoSOX reagent stock solution ( $5 \mathrm{mM}$ in DMSO (Sigma Aldrich, St. Louis, MO, USA)) in DMEM/F12 no phenol red buffer. At the end of light exposure, media were replaced with $100 \mu$ of MitoSOX reagent working solution; the well-plate was then incubated for $10 \mathrm{~min}$ at $37^{\circ} \mathrm{C}$ in the dark. Cells were further carefully washed 3 times with warm PBS; finally $100 \mu \mathrm{l}$ of PBS was added to wells. The fluorescent signal was read on an Infinite M1000 microplate reader (Tecan, Männedorf, Switzerland): $\lambda \uparrow=510 \mathrm{~nm}, \lambda \downarrow=580 \mathrm{~nm}$. Measured values were normalized according to control cells considered as 1 and also according to viability.

\subsection{Mitochondrial membrane potential assessment}

Mitochondrial membrane potential was measured using the Mito-ID membrane potential cytotoxicity kit (Enzo Life Sciences, Farmingdale, NY, USA). Carbonyl cyanide 3-chlorophenylhydrazone (CCCP, working solution was prepared in DMEM/F12 no phenol red buffer) was added $30 \mathrm{~min}$ before the end of light exposure to a few wells to abolish the mitochondrial membrane potential as a positive control (final concentration in wells was $8 \mu \mathrm{M})$. At the end of light exposure, the MitoID dye solution prepared according to the manufacturer's protocol was directly dispensed into each well; the well-plate was then incubated for $30 \mathrm{~min}$ at RT in the dark. The fluorescent signal was read on an Infinite M1000 microplate reader (Tecan, Männedorf, Switzerland): $\lambda \uparrow$ $=490 \mathrm{~nm}, \lambda \downarrow=590 \mathrm{~nm}$. Measured values were normalized with respect to control cells considered as 1 .

\subsection{Measurement of glutathione}

The rate of reduced and oxidized forms of glutathione was measured with the GSH/GSSG-Glo ${ }^{\mathrm{TM}}$ Assay kit (Promega, Madison, WI, USA). At the end of light exposure, cells were treated either with Total or Oxidized Glutathione Reagent for 5 min under shaking at RT. Luciferin Generation Reagent was then added to all the wells; the well-plate was incubated for $30 \mathrm{~min}$ at RT before adding the Luciferin Detection Reagent. Luminescence was read on a microplate reader Infinite M1000 microplate reader (Tecan, Männedorf, Switzerland). Measured values were normalized with respect to control cells considered as 1 and also with respect to viability. The ratio GSH/GSSG was calculated according to the manufacturer's protocol.

\subsection{Imaging}

Cells were fixed with $4 \%$ paraformaldehyde-PBS (Sigma-Aldrich) for $10 \mathrm{~min}$, then washed twice with PBS and imaged with the inverted Nikon TiE microscope (image recording via Metamorph 7.7). Images were then processed with the Fiji software (ImageJ version).

\subsection{0. $R T-q P C R$}

After the end of illumination, cells were washed and lysed; total RNA was extracted using a NucleoSpin RNA XS extraction kit (Macherey-Nagel, Düren, Germany). RNA quality and quantity were assessed using a ND-1000 spectrophotometer (Thermo Scientific, Waltham, Massachusetts, USA). cDNA was further synthesized from equal amounts of RNA using Multiscribe reverse transcriptase (TaqMan Reverse Transcription Reagents, Applied Biosystems, Life Technologies, Carlsbad, CA, USA) according to the manufacturer's protocol. Finally, cDNA were diluted in DNAse/RNAse free water (Gibco) to a final concentration of $5 \mathrm{ng} / \mu \mathrm{l}$. Real-time quantitative PCR was performed with $25 \mathrm{ng}$ of cDNA added to a $15 \mu \mathrm{l}$ solution of Applied Biosystems Mastermix (TaqMan Universal PCR Master Mix) and primers to a final volume of $20 \mu \mathrm{l}$. All primers and reagents were purchased from Applied Biosystems: GAPDH (Hs02786624_g1), HPRT1 (Hs02800695_m1), IL-6 (Hs00174131_m1), CXCL8 (Hs00174103_m1), TGFß2 (Hs00234244_m1), CCL2 (Hs00234140_m1), NFkB1 (Hs00765730_m1), GPx1 (Hs00829989_gH), SOD1 (Hs00533490_m1). Target cDNA was amplified using the 7300 Real-Time PCR system (Applied Biosystems). Changes in mRNA expression were calculated as $\Delta \Delta \mathrm{Ct}=\Delta \mathrm{Ct}_{\text {illuminated }}$ $\Delta \mathrm{Ct}_{\text {control }}$ with $\Delta \mathrm{Ct}=\mathrm{Ct}_{\text {target_gene }}-\mathrm{Ct}_{\mathrm{HK}_{\text {_gene }} \text {. }} \mathrm{Ct}$ means cycle threshold and HK_gene means housekeeping gene (HPRT for HCE and GAPDH for IOBA). Non-illuminated cells cultured in basal conditions were taken as controls.

\subsection{Statistical analysis}

All experiments were repeated at least three times in technical 
replicate. Statistical analyzes were performed using GraphPad (GraphPad Software, La Jolla, CA, USA). One- or two-way ANOVA analysis with repeated (time follow-up experiments) or non-repeated measures followed by False Discovery Rate multiple correction (twostage step-up method of Benjamini, Krieger and Yekutieli, false discovery rate $\mathrm{Q}=0.05$ ) were used. All data are presented as mean \pm SEM. Differences were considered significant when $\mathrm{p}<0.05$ $\left(*{ }^{\wedge}\right), \mathrm{p}<0.01\left(* * /^{\wedge}\right), \mathrm{p}<0.001\left(* * * /{ }^{\wedge \wedge}\right)$ or $\mathrm{p}<0.0001\left(* * * /^{\wedge \wedge n}\right)$.

\section{Acknowledgements}

We thank Coralie Barrau and William Rostène for insightful comments, Camille Ehrismann for technical support of the illumination systems and Karima Kessal for technical assistance and advices.

\section{Sources of funding}

This work was funded by Essilor International, within the frame of research collaboration with Sorbonne Université / Institut de la Vision.

\section{Conflicts of interest}

The authors report no conflicts of interest

\section{Appendix A. Supporting information}

Supplementary data associated with this article can be found in the online version at doi:10.1016/j.freeradbiomed.2018.07.012.

\section{References}

[1] J. Marshall, Understanding risks of phototoxicity on the eye, Point Vue, International Rev. Ophthalmic Opt. 〈http://www.pointsdevue.com/article/ understanding-risks-phototoxicity-eye $>$ (Accessed 7 November 2017).

[2] H.S. Lee, L. Cui, Y. Li, J.S. Choi, J. Choi, Z. Li, G.E. Kim, W. Choi, K.C. Yoon, Influence of light emitting diode-derived blue light overexposure on mouse ocular surface, PLoS One (2016), https://doi.org/10.1371/journal.pone.0161041.

[3] A.P. Cullen, Photokeratitis and other phototoxic effects on the cornea and conjunctiva, Int. J. Toxicol. (2002) 455-464, https://doi.org/10.1080/ 1091581029016988.

[4] J. Voke, Radiation effects on the eye. Part 3a - ocular effects of ultraviolet radiation, Optom. Today (1999) 27-32 (http://www.optometry.co.uk/pages/articles/arti cles1999.php\%5Cn C:\%5CLibrary\%5CVoke1999.pdf).

[5] P.L. Turner, E.J.W. Van Someren, M.A. Mainster, The role of environmental light in sleep and health: Effects of ocular aging and cataract surgery, Sleep. Med. Rev. 14 (2010) 269-280, https://doi.org/10.1016/j.smrv.2009.11.002.

[6] J. Voke, Radiation effects on the eye. Part 3b - ocular effects of ultraviolet radiation, Optom. Today (1999) 37-41 (http://www.optometry.co.uk/pages/articles/articles1999.php\%5Cn C:\%5CLibrary\%5CVoke1999b.pdf).

[7] F. Stapleton, M. Alves, V.Y. Bunya, I. Jalbert, K. Lekhanont, F. Malet, K. Na, D. Schaumberg, M. Uchino, J. Vehof, E. Viso, S. Vitale, The ocular surface TFOS DEWS II epidemiology report, Ocul. Surf. 15 (2017) 334-365, https://doi.org/10 1016/j.jtos.2017.05.003

[8] M. Wade, Symptoms of dry eye disease, Discov. Eye Found. (2015), 〈http:// discoveryeye.org/symptoms-of-dry-eye-disease/> (Accessed 6 November 2015).

[9] Tear Film \& Ocular Surface Society, DRY EYE REDEFINED: TFOS DEWS II REPORT, TFOS. 〈http://www.tfosdewsreport.org / (Accessed 10 November 2017).

[10] J.P. Craig, K.K. Nichols, J.J. Nichols, B. Caffery, H.S. Dua, E.K. Akpek, K. Tsubota, C.-K. Joo, Z. Liu, J. Daniel Nelson, F. Stapleton, TFOS DEWS II definition and classification report, Ocul. Surf. 15 (2017) 276-283, https://doi.org/10.1016/j.jtos. 2017.05.008.

[11] A. Réaux-le-Goazigo, A. Labbé, C. Baudouin, Melik-Parsadaniantz, Stéphane, La douleur oculaire chronique: mieux la comprendre pour mieux la traiter, Med./Sci. 33 (2017) 749-757.

[12] W. Hauser, Dry eye: a young Person's disease? Rev. Optom. (2017), 〈https://www. reviewofoptometry.com/article/dry-eye-a-young-persons-disease〉 (Accessed 6 November 2017).

[13] Text Request, How Much Time Do People Spend on Their Mobile Phones in2017?, Hackernoon. (n.d.). 〈https://hackernoon.com/how-much-time-do-people-spendon-their-mobile-phones-in-2017-e5f90a0b10a6〉 (Accessed 7 November 2017).

[14] J. Lupis, The State of Traditional TV: Updated With Q1 2017 Data, Mareketing Charts. (n.d.). 〈http://www.marketingcharts.com/featured-24817〉 (Accessed 7 November 2017).

[15] A. Yazici, E.S. Sari, G. Sahin, A. Kilic, H. Cakmak, O. Ayar, S.S. Ermis, Change in tear film characteristics in visual display terminal users, EJO 25 (2015) 85-89, https://doi.org/10.5301/ejo.5000525.
[16] M. Kaido, I. Toda, T. Oobayashi, M. Kawashima, Reducing short-wavelength blue light in dry eye patients with unstable tear film improves performance on tests of visual acuity, PLoS One 11 (2016) 1-10, https://doi.org/10.1371/journal.pone. 0152936.

[17] R. Courtin, B. Pereira, G. Naughton, A. Chamoux, F. Chiambaretta, C. Lanhers, F. Dutheil, Prevalence of dry eye disease in visual display terminal workers: a systematic review and meta-analysis, BMJ (2016), https://doi.org/10.1136/ bmjopen-2015-009675.

[18] M. Uchino, N. Yokoi, Y. Uchino, M. Dogru, M. Kawashima, A. Komuro, Y. Sonomura, H. Kato, S. Kinoshita, D. a. Schaumberg, K. Tsubota, Prevalence of dry eye disease and its risk factors in visual display terminal users: the Osaka study (e1), Am. J. Ophthalmol. 156 (2013) 759-766, https://doi.org/10.1016/j.ajo.2013.05. 040.

[19] A.J. Bron, C.S. de Paiva, S.K. Chauhan, S. Bonini, S. Jain, E. Knop, M. Markoulli, Y. Ogawa, V. Perez, Y. Uchino, N. Yokoi, D. Zoukhri, D.A. Sullivan, TFOS DEWS II pathophysiology report, Ocul. Surf. 15 (2017) 511-538, https://doi.org/10.1016/j. jtos.2017.05.004.

[20] E. Arnault, C. Barrau, P. Gondouin, K. Bigot, T. Villette, S. Picaud, D. CohenTannoudji, Phototoxic action spectrum on a retinal pigment epithelium model of age-related macular degeneration exposed to sunlight normalized conditions, PLoS One 8 (2013), https://doi.org/10.1371/journal.pone.0071398.

[21] K. Ogawa, Y. Kuse, K. Tsuruma, S. Kobayashi, M. Shimazawa, H. Hara, Protective effects of bilberry and lingonberry extracts against blue light-emitting diode light induced retinal photoreceptor cell damage in vitro, BMC Complement. Altern. Med. 14 (2014) 1-11.

[22] C. Roehlecke, U. Schumann, M. Ader, C. Brunssen, S. Bramke, H. Morawietz, R.H.W. Funk, Stress reaction in outer segments of photoreceptors after blue light irradiation, PLoS One 8 (2013) e71570, https://doi.org/10.1371/journal.pone. 0071570.

[23] I.K. Gipson, The ocular surface: the challenge to enable and protect vision, Ocul Surf. 48 (2010) 4390-4398, https://doi.org/10.1167/iovs.07-0770.The.

[24] C. Zinflou, P.J. Rochette, Free radical biology and medicine ultraviolet A-induced oxidation in cornea: characterization of the early oxidation-related events, Free Radic. Biol. Med. 108 (2017) 118-128, https://doi.org/10.1016/j.freeradbiomed. 2017.03.022.

[25] C. Cejka, J. Platenik, R. Buchard, V. Guryca, J. Sirc, M. Vejerazka, J. Crkovska, T. ARdan, J. Michalek, B. Brunova, J. Cejkova, Effect of two different UVA doses on the rabbit cornea and lens, Photochem. Photobiol. (2009) 794-800, https://doi. org/10.1111/j.1751-1097.2008.00478.x.

[26] A. Golu, I. Gheorghisor, A.T. Balasoiu, F. Balta, E. Osiac, L. Mogoanta, A. Bold, The effect of ultraviolet radiation on the cornea - experimental study, RJME 54 (2013) $1115-1120$.

[27] S.P. Gendron, P.J. Rochette, Modifications in stromal extracellular matrix of aged corneas can be induced by ultraviolet A irradiation, Aging Cell. (2015) 433-442, https://doi.org/10.1111/acel.12324.

[28] P. Dadoukis, I. Klagas, E. Papakonstantinou, Infrared irradiation alters the expression of matrix metalloproteinases and glycosaminoglycans in the cornea and crystalline lens, Graefes Arch. Clin. Exp. Ophthalmol. (2013) 1929-1936, https://doi. org/10.1007/s00417-013-2349-9.

[29] J. Lee, S. Kim, S. Lee, H. Kim, H. Ahn, Z. Li, Blue light - induced oxidative stress in human corneal epithelial cells: protective effects of ethanol extracts of various medicinal plant mixtures, Cornea 55 (2014) 4119-4127, https://doi.org/10.1167/ iovs.13-13441.

[30] M. Ayaki, Y. Niwano, T. Kanno, K. Tsubota, Blue light induces oxidative damage in human ocular surface cells in culture, ARVO 2015 Annu. Meet. Abstr. (2015).

[31] Y. Niwano, T. Kanno, A. Iwasawa, M. Ayaki, K. Tsubota, Blue light injures corneal epithelial cells in the mitotic phase in vitro, Br. J. Ophthalmol. 98 (2014) 990-992, https://doi.org/10.1136/bjophthalmol-2014-305205.

[32] H. Bin Hwang, H.S. Kim, Phototoxic effects of an operating microscope on the ocular surface and tear film, Cornea 33 (2014) 82-90, https://doi.org/10.1097/ ICO.0000000000000001.

[33] T. Ipek, M.P. Hanga, A. Hartwig, J. Wolffsohn, C. O'Donnell, Dry eye following cataract surgery: the effect of light exposure using an in-vitro model, Cont. Lens Anterior Eye (2017) 3-6, https://doi.org/10.1016/j.clae.2017.11.003.

[34] A. Denoyer, G. Rabut, C. Baudouin, Tear film aberration dynamics and vision-related quality of life in patients with dry eye disease, Ophthalmology 119 (2012) 1811-1818, https://doi.org/10.1016/j.ophtha.2012.03.004.

[35] A. Pauly, E. Brasnu, L. Riancho, F. Brignole-Baudouin, C. Baudouin, Multiple endpoint analysis of BAC-preserved and unpreserved antiallergic eye drops on a 3Dreconstituted corneal epithelial model, Mol. Vis. 17 (2011) 745-755 〈https://www. ncbi.nlm.nih.gov/pmc/articles/PMC3062522/pdf/mv-v17-745.pdf $\rangle$.

[36] C. Baudouin, P. Aragona, G. Van Setten, M. Rolando, M. Irkec, J.B. Del Castillo, G. Geerling, M. Labetoulle, S. Bonini, Diagnosing the severity of dry eye: a clear and practical algorithm, Br. J. Ophthalmol. 98 (2014) 1168-1176, https://doi.org/10. 1136/bjophthalmol-2013-304619.

[37] A. Denoyer, D. Godefroy, I. Celerier, J. Frugier, L. Riancho, F. Baudouin, W. Rostene, C. Baudouin, CX3CL1 expression in the conjunctiva is involved in immune cell trafficking during toxic ocular surface inflammation, Mucosa Immunol. 5 (2012) 703-711, https://doi.org/10.1038/mi.2012.43.

[38] E. Warcoin, C. Baudouin, C. Gard, F. Brignole-Baudouin, In vitro inhibition of NFAT5-mediated induction of CCL2 in hyperosmotic conditions by cyclosporine and dexamethasone on human HeLa-modified, PLoS One (2016) 1-19, https://doi org /10.1371/journal.pone.0159983.

[39] S. Seen, L. Tong, Dry eye disease and oxidative stress, Acta Ophtalmol. (2017) 1-9, https://doi.org/10.1111/aos.13526.

[40] H. Liang, C. Baudouin, P. Daull, J.-S. Garrigue, F. Brignole-Baudouin, Ocular safety 
of cationic emulsion of cyclosporine in an in vitro corneal wound-healing model and an acute in vivo rabbit model, Mol. Vis. 18 (2012) 2195-2204 〈http://www. pubmedcentral.nih.gov/articlerender.fcgi? artid $=3425577 \&$ tool $=$ pmcentrez\& rendertype $=$ abstract $>$.

[41] Y. Diebold, M. Calonge, A. Enrı, S. Callejo, R.M. Corrales, V. Sa, K.F. Siemasko, M.E. Stern, Characterization of a spontaneously immortalized cell line (IOBA-NHC) from normal human conjunctiva, IOVS 44 (2003), https://doi.org/10.1167/iovs. 03-0560.

[42] L. Tong, Y. Diebold, M. Calonge, J. Gao, M.E. Stern, R.W. Beuerman, Comparison of gene expression profiles of conjunctival cell lines with primary cultured conjunctival epithelial cells and human conjunctival tissue, Gene Expr. 14 (2009) $265-278$.

[43] A. Enríquez-De-Salamanca, V. Calder, J. Gao, G. Galatowicz, C. García-vázquez, I. Fernández, M.E. Stern, Y. Diebold, M. Calonge, Cytokine cytokine responses by conjunctival epithelial cells: an in vitro model of ocular inflammation, Cytokine 44 (2008) 160-167, https://doi.org/10.1016/j.cyto.2008.07.007.

[44] A. Guzman-Aranguez, M.J. Pérez de Lara, J. Pintor, Hyperosmotic stress induces ATP release and changes in P2 $\times 7$ receptor levels in human corneal and conjunctival epithelial cells, Purinergic Signal. 13 (2017) 249-258.

[45] Y. Ren, H. Lu, P.S. Reinach, Q. Zheng, J. Li, Q. Tan, H. Zhu, W. Chen, Hyperosmolarity-induced AQP5 upregulation promotes inflammation and cell death via JNK1/2 Activation in human corneal epithelial cells, Sci. Rep. 7 (2017) 1-11, https://doi.org/10.1038/s41598-017-05145-y.

[46] H. Zhan, H. Towler, V.L. Calder, The immunomodulatory role of human conjunctival epithelial cells, IOVS 44 (2003) 3906-3910, https://doi.org/10.1167/ iovs.02-0665.

[47] C. Baudouin, P.-J. Pisella, H.-X. Thanh, Surface Oculaire Rapport 2015, Elsevier, Masson, 2015.

[48] S. Pflugfelder, C. de Paiva, The pathophysiology of dry eye disease: what we know and future directions for research, Am. Acad. Ophtalmol. 124 (2017) 4-13, https:// doi.org/10.1016/j.ophtha.2017.07.010.

[49] A. Macri, C. Scanarotti, A.M. Bassi, S. Giuffrida, G. Sangalli, C.E. Traverso, Evaluation of oxidative stress levels in the conjunctival epithelium of patients with or without dry eye, and dry eye patients treated with preservative-free hyaluronic acid $0.15 \%$ and vitamin B12 eye drops, Cornea (2015) 425-430, https://doi.org/ 10.1007/s00417-014-2853-6.

[50] Y. Uchino, T. Kawakita, T. Ishii, N. Ishii, New mouse model of dry eye disease: oxidative stress affects functional decline in the lacrimal gland, Cornea 31 (2012) 63-67.

[51] T.H. Wakamatsu, M. Dogru, K. Tsubota, Tearful relations: oxidative stress, inflammation and eye diseases, Arq. Bras. Oftalmol. 2 (2008) 72-79.

[52] S.K. Ward, T.H. Wakamatsu, M. Dogru, O.M. a. Ibrahim, M. Kaido, Y. Ogawa, Y. Matsumoto, A. Igarashi, R. Ishida, J. Shimazaki, C. Schnider, K. Negishi, C. Katakami, K. Tsubota, The role of oxidative stress and inflammation in dry eye disease, Cornea 28 (2009) 70-74, https://doi.org/10.1167/iovs.09-4130.

[53] P. Newsholme, E. Rebelato, F. Abdulkader, M. Krause, A. Carpinelli, R. Curi, Reactive oxygen and nitrogen species generation, antioxidant defenses, and b-cell function: a critical role for amino acids, J. Endocrinol. 214 (2012) 11-20, https:// doi.org/10.1530/JOE-12-0072.

[54] G.P. Bienert, J.K. Schjoerring, T.P. Jahn, Membrane transport of hydrogen peroxide, Biochim. Biophys. Acta - Biomembr. 1758 (2006) 994-1003, https://doi.org/10. 1016/j.bbamem.2006.02.015.

[55] N. Ballatori, S.M. Krance, S. Notenboom, S. Shi, K. Tieu, C.L. Hammond, Glutathione dysregulation and the etiology and progression of human diseases, Biol. Chem. 390 (2009) 191-214, https://doi.org/10.1515/BC. 2009.033.Glutathione.

[56] I. Rebrin, R.S. Sohal, Pro-oxidant shift in glutathione redox state during aging Igor, Adv. Drug Deliv. Rev. 60 (2008) 1545-1552, https://doi.org/10.1016/j.addr.2008. 06.001.Pro-oxidant.

[57] Y. Chen, G. Menta, V. Vasiliou, Antioxidant defenses in the ocular surface, Ocul. Surf. 7 (2009) 176-185, https://doi.org/10.1002/nbm.3066.Non-invasive.

[58] G. Gupta, R.K. Chaitanya, M. Golla, R. Karnati, Allethrin toxicity on human corneal epithelial cells involves mitochondrial pathway mediated apoptosis, Toxicol. Vitr. 27 (2013) 2242-2248, https://doi.org/10.1016/j.tiv.2013.09.011.

[59] J. Gao, R. Sana, V. Calder, M. Calonge, W. Lee, L.A. Wheeler, M.E. Stern, Mitochondrial permeability transition pore in inflammatory apoptosis of human conjunctival epithelial cells and T cells: effect of cyclosporin A, Cornea 54 (2013) 4717-4733, https://doi.org/10.1167/iovs.13-11681.

[60] D.D. Newmeyer, S. Ferguson-Miller, Mitochondria: releasing power for life and unleashing the machineries of death, Cell 112 (2003) 481-490, https://doi.org/10 1016/S0092-8674(03)00116-8.

[61] B. Kadenbach, S. Arnold, I. Lee, M. Hüttemann, The possible role of cytochrome c oxidase in stress-induced apoptosis and degenerative diseases, Biochim. Biophys. Acta - Bioenergy 1655 (2004) 400-408, https://doi.org/10.1016/j.bbabio.2003.06. 005.

[62] M. Forkink, G.R. Manjeri, D.C. Liemburg-Apers, E. Nibbeling, M. Blanchard, A. Wojtala, J.A.M. Smeitink, M.R. Wieckowski, P.H.G.M. Willems, W.J.H. Koopman, Mitochondrial hyperpolarization during chronic complex i inhibition is sustained by low activity of complex II, III, IV and v, Biochim. Biophys. Acta - Bioenerg. 1837 (2014) 1247-1256, https://doi.org/10.1016/j.bbabio.2014. 04.008.

[63] A. Perl, P.J. Gergely, G. Nagy, A. Koncz, K. Banki, Mitochondrial hyperpolarization: a checkpoint of T-cell life, death and autoimmunity, Trends Immunol. 25 (2004) 360-367, https://doi.org/10.1016/j.it.2004.05.001.Mitochondrial.

[64] K. Banki, E. Hutter, N. Gonchoroff, A. Perl, Elevation of mitochondrial transmembrane potential and reactive oxygen intermediate levels are early events and occur independently from activation of caspases in Fas signaling, J. Immunil. 162 (1999) 1466-1479.

[65] A.M. De Sousa Leal, Violacein induces cell death by triggering mitochondrial membrane hyperpolarization in vitro, BMC Microbiol. 15 (2015) 4-11, https://doi. org/10.1186/s12866-015-0452-2.

[66] A. Bajić, M. Spasić, P.R. Andjus, D. Savić, A. Parabucki, A. Nikolić-Kokić, I. Spasojević, Fluctuating vs. continuous exposure to H2O2: the effects on mitochondrial membrane potential, intracellular calcium, and NF- $\mathrm{kB}$ in Astroglia, PLoS One 8 (2013) 1-10, https://doi.org/10.1371/journal.pone.0076383.

[67] H. Selye, C. Fortier, Adaptive reactions to stress, Assoc. Res. Nerv. Ment. Diseas. 29 (1949) 3-18.

[68] T.L. Merry, M. Ristow, Mitohormesis in exercise training, Free Radic. Biol. Med. (2015), https://doi.org/10.1016/j.freeradbiomed.2015.11.032.

[69] M. Ristow, K. Zarse, How increased oxidative stress promotes longevity and metabolic health: the concept of mitochondrial hormesis (mitohormesis), Exp. Gerontol. 45 (2010) 410-418, https://doi.org/10.1016/j.exger.2010.03.014.

[70] M. Ristow, K. Schmeisser, Mitohormesis: promoting health and lifespan by increased levels of reactive oxygen species (ROS), Dose-Response 12 (2014) 288-341, https://doi.org/10.2203/dose-response.13-035.Ristow.

[71] N. Deschamps, C. Baudouin, Dry eye and biomarkers : present and future, Curr. Ophthalmol. Rep. (2013) 65-74, https://doi.org/10.1007/s40135-013-0008-2.

[72] U. Spandau, A. Toksoy, S. Verhaart, R. Gillitzer, F.E. Kruse, High expression of chemokines Gro-a (CXCL-1), IL-8 (CXCL-8), and MCP-1 (CCL-2) in inflamed human corneas in vivo, Lab. Sci. 121 (2003) 2-8.

[73] S.L. Deshmane, S. Kremlev, S. Amini, B.E. Sawaya, Monocyte chemoattractant protein-1 (MCP-1): an overview, J. Interf. Cytokine Res. 29 (2009) 313-326, https://doi.org/10.1089/jir.2008.0027.

[74] S. Saika, TGF $\beta$ pathobiology in the eye, Lab. Investig. 86 (2006) 106-115, https:// doi.org/10.1038/labinvest.3700375.

[75] E.-J. Chang, Y. Sun, Im, E.P. Kay, J.Y. Kim, J.E. Lee, H.K. Lee, The role of nerve growth factor in hyperosmolar stress induced apoptosis, J. Cell. Physiol. 216 (2008) 69-77, https://doi.org/10.1002/jcp.21377.

[76] M.P. Cabrera, R.H. Chihuailaf, Antioxidants and the integrity of ocular tissues, Vet. Med. Int. 2011 (2011) 1-8, https://doi.org/10.4061/2011/905153.

[77] M.A. Shatos, J.D. Ríos, Y. Horikawa, R.R. Hodges, E.L. Chang, C.R. Bernardino, P.A.D. Rubin, D.A. Dartt, Isolation and characterization of cultured human conjunctival goblet cells, Investig. Ophthalmol. Vis. Sci. 44 (2003) 2477-2486, https:// doi.org/10.1167/iovs.02-0550.

[78] D.A. Dartt, R.R. Hodges, D. Li, M.A. Shatos, K. Lashkari, C.N. Serhan, Conjunctival goblet cell secretion stimulated by leukotrienes is reduced by resolvins D1 and E1 to promote resolution of inflammation, J. Immunol. 186 (2011) 4455-4466, https:// doi.org/10.4049/jimmunol.1000833.

[79] M. Dutot, H. Liang, T. Pauloin, F. Brignole-Baudouin, C. Baudouin, J.-M. Warnet, P. Rat, Effects of toxic cellular stresses and divalent cations on the human P2 $\times 7$ cell death receptor, Mol. Vis. 14 (2008) 889-897〈http://www.ncbi.nlm.nih.gov/ pubmed/18490962\%5Cnhttp://www.pubmedcentral.nih.gov/articlerender.fcgi? artid $=$ PMC2386509>

[80] C. Mehanna, C. Baudouin, F. Brignole-Baudouin, Spectrofluorometry assays for oxidative stress and apoptosis, with cell viability on the same microplates: a multiparametric analysis and quality control, Toxicol. Vitr. 25 (2011) 1089-1096, https://doi.org/10.1016/j.tiv.2011.03.007.

[81] A. Pauly, F. Brignole-Baudouin, J.M. Guenoun, L. Riancho, P. Rat, J.M. Warnet, C. Baudouin, Comparative study of topical anti-allergic eye drops on human conjunctiva-derived cells: responses to histamine and IFN $\gamma$ and toxicological profiles, Graefe'S. Arch. Clin. Exp. Ophthalmol. 245 (2007) 534-546, https://doi.org/10. 1007/s00417-006-0353-z. 